\title{
Nonlinear numerical simulation of punching shear beha- vior of reinforced concrete flat slabs with shear-heads
}

\author{
Dan V. BOMPA*, Ahmed Y. ELGHAZOULI \\ Department of Civil and Environmental Engineering, Imperial College London, London SW7 2AZ, UK \\ ${ }^{*}$ Corresponding author.E-mail: d.bompa@imperial.ac.uk
}

(C) The Author(s) 2019. This article is published with open access at link.springer.com and journal.hep.com.cn

\begin{abstract}
This paper examines the structural response of reinforced concrete flat slabs, provided with fullyembedded shear-heads, through detailed three-dimensional nonlinear numerical simulations and parametric assessments using concrete damage plasticity models. Validations of the adopted nonlinear finite element procedures are carried out against experimental results from three test series. After gaining confidence in the ability of the numerical models to predict closely the full inelastic response and failure modes, numerical investigations are carried out in order to examine the influence of key material and geometric parameters. The results of these numerical assessments enable the identification of three modes of failure as a function of the interaction between the shear-head and surrounding concrete. Based on the findings, coupled with results from previous studies, analytical models are proposed for predicting the rotational response as well as the ultimate strength of such slab systems. Practical recommendations are also provided for the design of shear-heads in RC slabs, including the embedment length and section size. The analytical expressions proposed in this paper, based on a wide-ranging parametric assessment, are shown to offer a more reliable design approach in comparison with existing methods for all types of shear-heads, and are suitable for direct practical application.
\end{abstract}

KEYWORDS non-linear numerical modelling, concrete damage plasticity, RC flat slabs, shear-heads, punching shear

\section{Introduction}

Brittle failures, which can occur at the slab-column connection, may typically be prevented through drop panels or by reinforcing the critical region with transverse bars [1-3] or structural steel inserts [4-11]. The performance of a flat slab with transverse reinforcement is however strongly dependent on the arrangement, type and size as well as bond characteristics of the rebars. On the other hand, shear-head systems typically translate the weak section, both in bending and shear, outside of the shearhead region $[4,12]$. Early interest in shear-head configurations was shown with the development of high-rise structures in the United States [13,14]. Early tests on such systems showed that they can offer reliable structural response at the connection [15]. The first tests on fully embedded shear-heads against punching shear were carried out tests on flat slabs with cruciform shear-head systems

Article history: Received Feb 6, 2019; Accepted Mar 11, 2019 consisting of perpendicular Channel or I-sections (Figs. 1(a)-1(c)), placed between the longitudinal reinforcement layers. These showed an increase in punching shear strength by up to $75 \%$ in comparison to reference cases without shear-heads [6].

In Europe, tests on $140 \mathrm{~mm}$ flat slabs provided with fully embedded cruciform I-section shear-heads with varying embedment lengths subjected to axial load and unbalanced moment with eccentricities around 0.25 showed an increase in ultimate capacity between $40 \%$ and $70 \%$ as a function of the shear-head embedment length [16]. Development tests on shear-head systems made of inverted wide tee steel beams positioned in a cruciform arrangement also showed enhancement of punching shear strength of 240 and $300 \mathrm{~mm}$ slabs in the range of $65 \%$ in comparison their non-reinforced counterparts. As for other cruciform shear-head systems, rupture occurred at the tip of the shearhead, showing an effective force flow as the load was transferred to the column by shear in the web and tension action in the connection plates of the shear-heads [17]. 
Other tests made use of fully and partially embedded closed-box shear-heads which led to an increase in punching shear strength by about four times and a twofold reduction in the supporting moments $[4,18]$.

The crack patterns from tests on large-scale flat slabs provided with closed-box shear-heads and practical slab thicknesses, showed responses governed by tangential cracks around the shear-head, as well as straight radial cracks [19]. This indicated that the curvatures in the radial direction are concentrated around the relatively rigid shearhead acting as an enlarged column support, similar to a conventional column support (Fig. 1(d)). Moreover, tests on $16 \mathrm{~mm} \times 120 \mathrm{~mm}$ thick model slabs and 4 large-scale $3 \mathrm{~m} \times 3 \mathrm{~m}$ and $250 \mathrm{~mm}$ thick specimens investigated the optimal shear-head configuration and their effect on punching shear capacity [20]. Other intricate shear-head systems exist, including for example composite cruciform systems consisting of vertical steel plates acting as shearlegs to which headed studs are welded for composite action combined with special steel-endplates for strut support [21].

Nonlinear finite element simulations can offer insights into the structural behavior of RC and composite steelconcrete elements [22-24]. For a reliable computational representation of the characteristics of concrete materials under loading, a significant number of studies were carried out. Concrete is a relatively weak material in tension and relatively strong in compression with compressive-totensile strength ratio of about ten, and has a distinct postpeak behavior in compression and tension [25]. It is widely accepted that in tension a crack is initiated when the tensile stress exceeds the tensile strength (i.e., Rankine criterion) and the crack is perpendicular to the principal tensile strain. Constitutive models employed in engineering practice are typically based on a continuum approach. The cracks in concrete were represented by strain softening in the stressstrain curve leading to mesh-dependent results [26], particularly since with a finer mesh size, the fracture energy decreases.

Further fictitious and smeared crack models, in which the stress is represented in terms of relative displacement instead of strains, which account for cracks being located within and integration cell, were developed $[27,28]$. The latter, referred to as weak discontinuity approaches allow for the initiation of several cracks to initiate in a single element/cell. The introduction of a crack band model with constant fracture energy, in which the strain is function of a crack width and a characteristic element length, eliminated partially the mesh-dependency [26]. Moreover, by accounting for an extremely fine mesh size in the fracture process zone, mesh independency can be achieved [29]. Such methods were successfully employed for modeling prestressed concrete beams with different cross sections and different failure mechanisms (i.e., bending, shear, and anchorage failure), particularly since both pull-out and splitting failure characteristics were considered through an explicit modeling of the bond-slip behavior [29].

To overcome limitations of conventional modeling approaches in tension, computational fracture techniques were developed. These can be classified as either discrete or continuum-based such as remeshing procedures with extraneous crack path determination [30], local displacement [31] and strain enrichments [32], edges repositioning [33,34], fixed-mesh element erosion [35], smeared band algorithms [36], among others. Non-discrete approaches such as element deletion methods are also capable of predicting arbitrary crack paths [37]. An alternative is adaptive remeshing, yet this may be computationally expensive when multiple cracks exist, and the accuracy decreases with highly nonlinear issues [38]. For additional

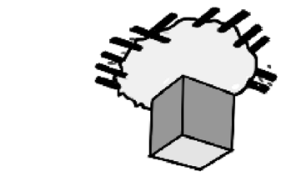

(a)

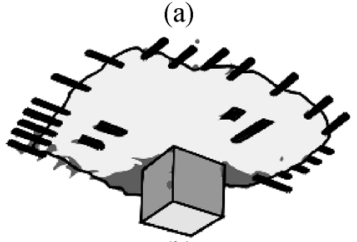

(b)

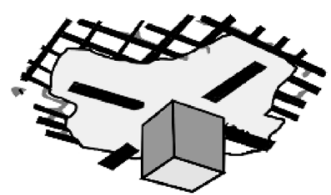

(c)

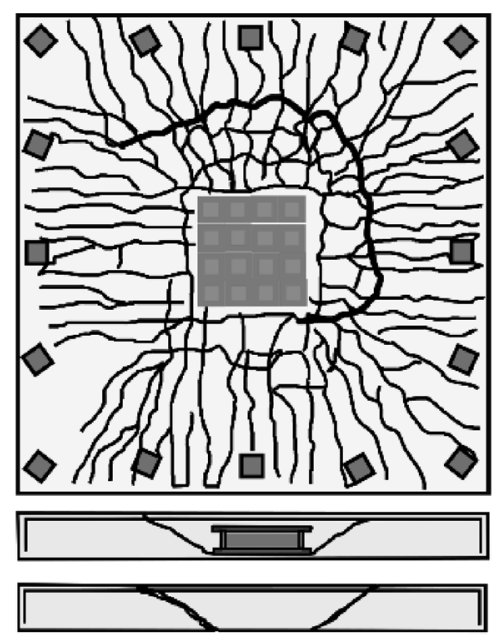

(d)

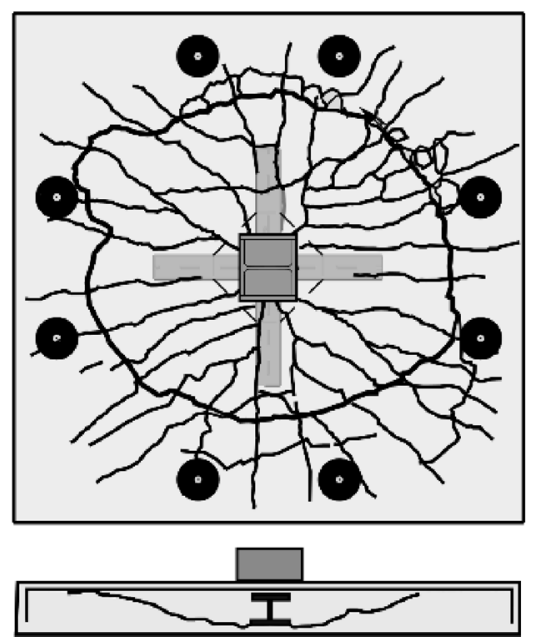

(e)

Fig. 1 Schematic of failure surfaces for specimens with and without cruciform shear-heads [6]: (a) AN-1, (b) AC-1, (c) AH-1; (d) crack distribution for closed box shear-heads [19]; (e) crack patterns for hybrid RC flat slabs with cruciform shear-heads [12]. 
inter-element-separation methods [39] crack growth develops at element edges and implicitly results are sensitive to mesh size. Discrete crack modeling in finite elements with remeshing was also investigated [40]. Based on an enrichment at the element level, embedded elements (EFEM) can predict arbitrary cracks without remeshing and are considered relatively inexpensive computationally, having an opportunity as being incorporated in commercial programs [41]. Also, novel approaches the extended finite element methods (XFEM) may be a viable option for practical implementation as the crack kinematics is captured by overlapping elements rather than by the addition of supplementary degrees of freedom [42].

On the other hand, more attractive methods to predict fracture of materials are meshfree methods, which are an alternative to finite elements for crack propagation $[43,44]$. In addition to the advantage of being more flexible because of the lack of a mesh, they have the non-local interpolation character which provides higher smoothness and continuity [45]. The method is applicable to nonlinear problems, problems with moderate to severe cracking and deformable interfaces [46]. It has been successfully applied for predicting the static response of reinforced and prestressed concrete beams as well as for assessing the response of concrete slabs under dynamic loading, in which the concrete is discretised in particles, while the reinforcement with elements $[47,48]$. In these methods, crack can be arbitrarily oriented, but its growth is represented discretely by activation of crack surfaces at individual particles, hence no representation of the crack topology is needed [43]. More advanced meshfree techniques for two and tri-dimensional modeling involve splitting particles located on opposite sides of the associated crack segments to describe the crack kinematics $[48,49]$.

As an extension of the classical smeared approach to fracture, somewhat between purely cohesive formulations and the smeared modeling, injection of continuum softening elements in the fracture process region were considered [50]. Through this technique, edge rotation around crack front nodes in surface discretisation is produced, while each rotated edge is duplicated to represent the crack path. To guarantee enough resolution in the definition of the crack paths, a local remeshing algorithm based on the phase field values at the lower and upper shell faces is introduced. In this two-stage local remeshing algorithm, edge-based element subdivision and node repositioning are performed [51]. Novel crack propagation algorithms, independent of particular constitutive laws and specific element technology, based on a localization limiter in the form of the screened Poisson equation with local remeshing, allow to capture strain localization in plain and reinforced concrete elements with good resolution in both two and three-dimensional problems [52,53].

Models to represent the post-peak response of materials in tension and compression such as coupled damageplasticity models, are regularly employed in practical modeling. In such models, the physical interpretation of damage is introduced as the specific damage surface area [54]. Depending of the main characteristics of the material, the damage can be isotropic (scalar) or anisotropic (tensor) [55]. Anisotropic damage models for brittle materials, such as concrete, are often complex and a combination with plasticity and application to structural analysis can be tedious [56]. Conversely, isotropic damage models are more attractive due to relatively simple combination with stress-based plasticity models formulated in the effective (undamaged) space [57], where the effective stress is defined as the average micro-scale stress acting on the undamaged material between micro-defects [55]. Although relatively simplified, this representation captures the main characteristics of the concrete response.

To avoid previously mentioned mesh-dependency problems the crack band model with constant facture energy in which the tensile response is a function of the characteristic element length, may be considered. Models employing such approaches were able to predict the ultimate strength and deformational response of plain and reinforced concrete members (e.g., localized behavior under direct shear and tension [58,59], assessment of a long-term behavior [60], RC flat slabs with and without shear reinforcement under static loading [61-63], RC hybrid beams in shear and flexure [64-67]). However, detailed numerical studies on flat slabs with shear-heads are relatively limited and have typically focused on hybrid connections between steel columns and RC floors. Previous assessments on hybrid and RC elements have highlighted the influence of key parameters which govern the performance of shear-heads in hybrid flat slabs similar to the member depicted in Fig. 1(e) [68-70]. However, previous studies were limited in terms of scope and parameter ranges, and hence did not permit the development of analytical models and guidance suitable for practical application.

Although shear-heads are widely considered as reinforcing systems against punching shear in practice [71], research studies on $\mathrm{RC}$ and hybrid configurations are constantly carried out $[8,9,11,12,30,68-70,72-76]$ and such systems are typically recommended for practical application [77], codified guidance is comparatively limited. For example, no specific provisions are stipulated in Eurocode 2 [78], while the Model Code 2010 [79] offers some guidance for the design of flat slabs with closed-box shear-heads. In contrast, ACI318-14 [80] offers detailed guidance for cruciform shear-heads, largely based on the limited tests data reported by Corley and Hawkins [6], while closed-box shear-heads are not addressed. Current guidelines are therefore limited to specific shear-head types, thus hindering a wider application. Observations from previous studies indicate that the punching shear resistance of flat slabs with shear-heads depends not only 
on the typical shear-design parameters such as shear depth, concrete strength and support size but also on the geometry, deformation response and strength of the individual elements of the shear-head.

This paper deals with the ultimate behavior of cruciform as well as closed-box shear-head systems fully embedded in $\mathrm{RC}$ flat slabs at interior RC columns through threedimensional nonlinear finite element assessments. After validating the numerical procedures against three series [6,20,81] (Figs. 2(a)-2(f)) which contained RC flat slabs with and without shear-heads, the results of detailed parametric investigations are presented and discussed. The parameters examined include the type, shape, embedment length, section size and layout of the shear-head system as well as flat slab dependent parameters such as thickness, concrete strength, reinforcement ratio, and support size. The shear-head configurations investigated in this paper are depicted in Figs. 2(g)-2(i): cruciform shear-heads made of welded back-to-back channel or I section (CRH), cruciform shear heads made of two pairs of channels at the support region (CTP) and closed-box shear-heads (CBX). The numerical results obtained enable a direct assessment of the ultimate behavior in terms of both strength and deformation characteristics, and also enable an assessment of the failure surface as a function of the shear-head configuration. Based on the findings, coupled with results from previous studies, analytical models are proposed for predicting the rotational response as well as the ultimate

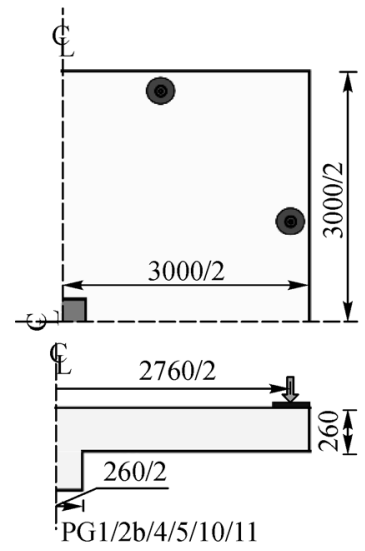

(a)

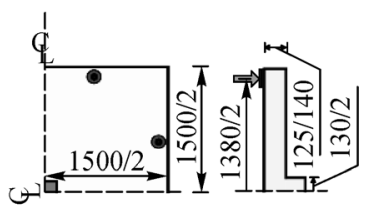

PG6/7/8/9

(b)

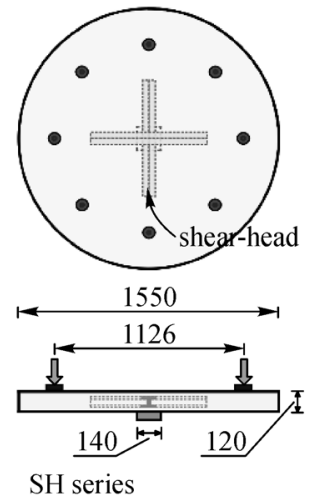

(e)

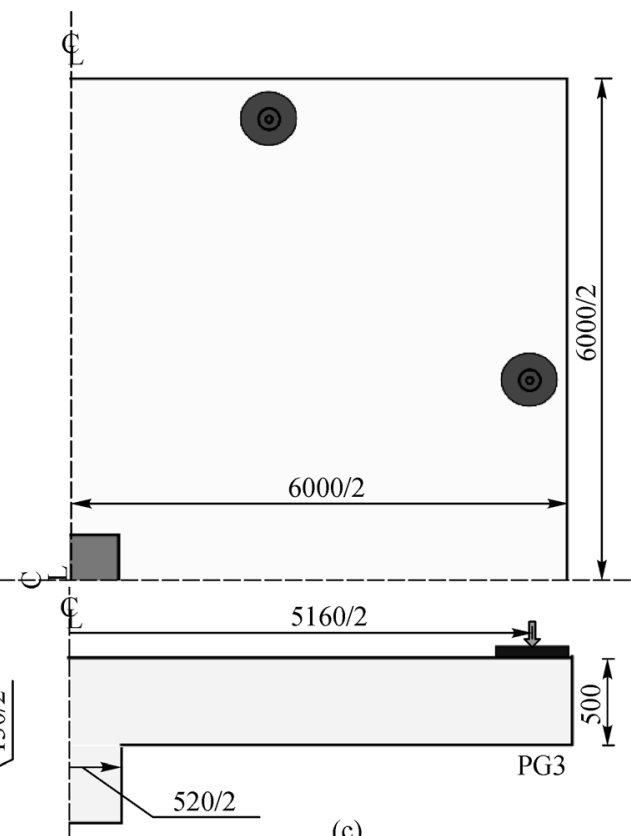

(c)

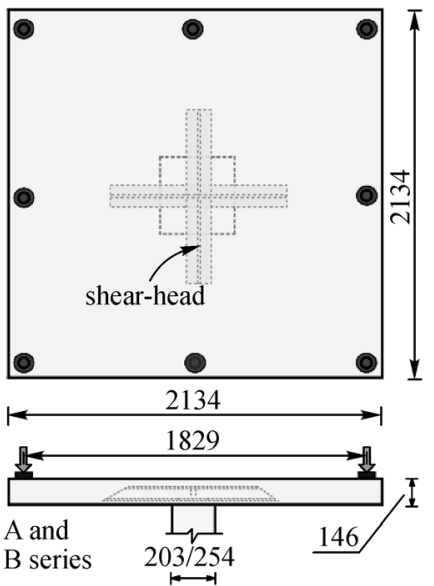

(f)

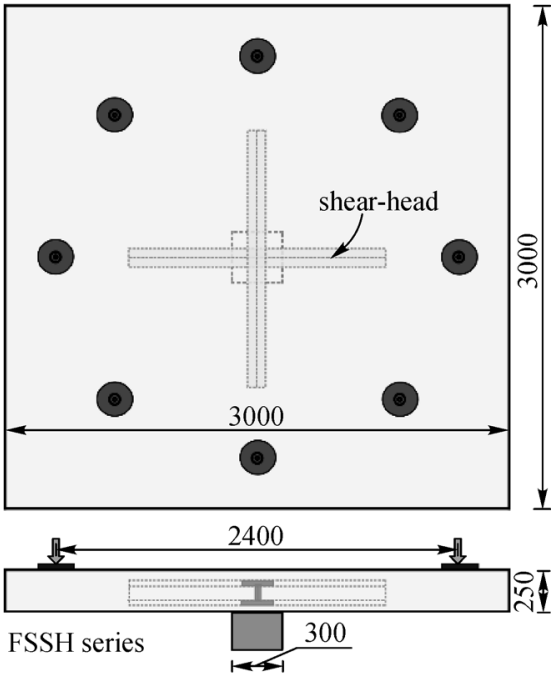

(d)

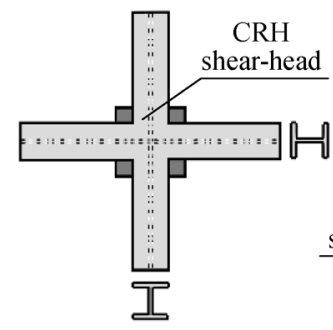

(g)

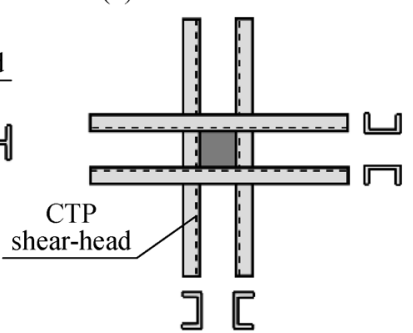

(h)

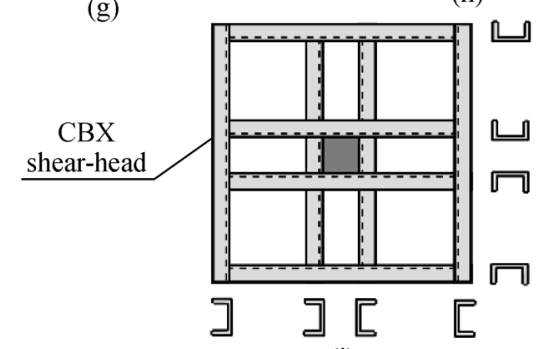

(i)

Fig. 2 Schematic representation of (a) full scale specimens PG1, PG2b, PG5, PG10, PG11; (b) half scale specimens PG6, PG7, PG8, PG9; (c) double scale specimen PG3 from Guandalini [81]; (d) FSSH series; (e) SH series from Chana and Birjandi [20]; (f) A and B series (Corley and Hawkins [6]); cruciform shear-heads made of (g) welded back-to-back channel or I section (CRH); (h) two pairs of channels at the support region (CTP) shear-heads; (i) closed-box shear-heads (CBX). 
strength of such slab systems. The proposed models are shown to offer a reliable and practical approach for a wide range of shear-head types and configurations.

\section{Numerical simulations}

The numerical simulations described in this section were carried out using the nonlinear finite element (FE) program ABAQUS [82] in order to obtain detailed insights into the structural response of RC flat slabs provided with cruciform and closed-box shear-heads at connections to interior $\mathrm{RC}$ columns. After discussing the modeling procedures and constitutive parameters for the concrete, reinforcement and structural steel, validations are carried out against 36 flat slab specimens extracted from three experimental programmes.

\subsection{Modeling procedures}

Three-dimensional (3D) models were constructed using double-symmetry to represent a quarter of an RC flat-slab specimens (Figs. 3(a)-3(b)). Eight node brick elements with reduced integration (C3D8R) were employed for the concrete slab, steel shear-heads and reaction plates, while 3D truss elements (T3D2) were used for the longitudinal reinforcement. The contact between the shear-head arms and the concrete body was represented using an exponential decay friction law described later. In all models, the reinforcement was embedded in the concrete body and assigned with full bond conditions. The reaction plates were connected to the concrete body by considering full interaction. These were assigned with elastic steel material properties, as they were overdesigned to remain in elastic regime. Pinned boundary conditions were assigned to reference points connected through link multi-point constraints to the reaction plates, while member displacements were applied in the same manner through tie multipoint constraints. The Newton-Raphson approach was adopted for the numerical integration procedure.

The 'concrete damaged plasticity' model (CDP) was used to represent the tri-axial behavior of concrete. For this, the potential yield function is controlled by the effective stress values, the bi-axial behavior of concrete $\left(f_{\mathrm{b}_{0}} / f_{\mathrm{c}}=1.16\right)$ and $K_{\mathrm{c}}=2 / 3$ that governs the shape of the deviatoric plane. The CDP model accounts for a nonassociated potential plastic flow, in which the plastic volume expansion is not proportional to the increase in stresses. This is represented in the plastic potential flow function by the dilation angle $\varphi$ measured in the p-q plane at high confining pressure and surface eccentricity $(\varepsilon=$ $0.1)$. The constitutive model requires uniaxial stress $(\sigma)$ strain $(\varepsilon)$-damage $\left(d_{\mathrm{i}}\right)$ relationships for the compression and tension behavior. In this study, a plastic stiffness degradation scheme, typical for coupled damage-plastic concrete constitutive models was adopted.
Before crushing in compression or cracking in tension, no degradation occurs and the plastic strains are equal to the inelastic strains. Beyond these points, the stiffness reduction enables the development of irreversible plastic strains that are directly proportional to the stress decrease [83]. The damage in compression $d_{\mathrm{c}}$ and damage in tension $d_{\mathrm{t}}$ parameters are also part of the variable field output of the FE environment. They allow direct interpretation of the stress state within different regions of the members, illustrated by compression and tension damage patterns, and member stiffness degradation. Established on a continuum approach, in which no physical separation is created in the model mesh, tension damage mesh regions provide an effective way to illustrate the kinematic aspects of crack development.

The compressive stress-strain $\sigma-\varepsilon$ relationship illustrated in Fig. 3(c) was defined using the Eurocode 2 [78] recommendation for nonlinear structural analysis, while the compressive constitutive properties (elastic modulus $E_{\mathrm{c}}$, strain at crushing $\varepsilon_{\mathrm{c} 1}$ and concrete tensile strength $f_{\mathrm{ct}}$ ) were assessed from the reported concrete strength $f_{\mathrm{c}}$. A factor of 0.8 was used to convert cube $f_{\mathrm{c} \text {, cube }}$ to cylinder $f_{\mathrm{c}}$ compressive strength where necessary, as typically considered in Eurocode 2 for mean concrete cylinder strengths below $68 \mathrm{MPa}$ [78]. In tension, linear-elastic behavior was considered up to cracking, followed by a bi-linear tension softening law extracted from a nonlinear model [84]. The numerical input was converted into inelastic cracking strain $\varepsilon_{\mathrm{ct}, i}$ using the concept of equivalent crack length in which the crack displacement $w_{i}$ up to $w_{\max }=160 \mu \mathrm{m}$, is divided by the characteristic length of the element $l_{\mathrm{ch}}$. The characteristic length of a 3D element is the cubic root of the volume of the mesh element $V_{\mathrm{e}}$. In the uniaxial post-peak tension regime, the damage is assumed to grow linearly from 0 to 0.9 . Such ranges were also employed in other studies from Ref. [23]. The maximum tension damage scalar (0.9) corresponds to a maximum crack displacement of $w_{\max }=160 \mu \mathrm{m}$, which is divided by the characteristic length of the element $l_{\mathrm{ch}}$, as mentioned before. Beyond this value, the damage scalar is subsequently held constant to preserve a residual stiffness and strength [23]. Both structural and reinforcement steels were modeled using bi-linear elasto-plastic material properties with hardening (Fig. 3(d)).

A numerical investigation carried out previously by the authors on hybrid RC flat slabs connected to steel columns was used as a reference for the definition of the governing constitutive and geometrical parameters [69]. These parameters were first calibrated with the models of Specimens PG1 without shear-heads [81], Specimens SH-1 and SH-2 [20], and Specimens AN-1 and AC-1 [6], and then applied to all other validation cases as discussed in the following section. The parameters varied in the sensitivity analysis were the dilation angle $\varphi$, mesh size, and the uniaxial tension material post-peak representation. Detailed results of the sensitivity analysis are only 
presented in Fig. 4 for Specimen PG1, while the complete load-displacement curves are given for all models of the three test series.

In terms of mesh sensitivity, the results were largely independent of the size $l_{\mathrm{m}}$ for the model of PG1 (Fig. 4(a)), when $l_{\mathrm{m}}$ varies from $h / 5$ to $h / 10$ ( $h$ : flat slab thickness). The use of a fracture dependent post-peak tension behavior for concrete allowed tension damage localization as a function of the chosen mesh size. The mesh sensitivity for models with low $\rho_{\mathrm{l}}$, provided with coarser mesh $\left(l_{\mathrm{m}}=h / 5\right)$, showed unrealistic rigid behavior in the post-cracking regime, primarily due to the delayed cracking as a result of poor propagation of tension damage in the continuum. A value of $l_{\mathrm{m}}=h / 7$ was found to be satisfactory in the models described here for RC slabs without shear-heads while $l_{\mathrm{m}}=$ $h / 10$ was suitable for slabs with shear-heads. In addition to this, the influence of the accounted stress transfer through cracked interfaces was investigated by accounting for three post-cracking strain distributions (Fig. 4(b)). Nonlinear representation of the post-peak tension behavior was chosen as opposed to linear and bi-linear laws, since the latter two produced stiffer numerical response, particularly for members with low $\rho_{1}$.

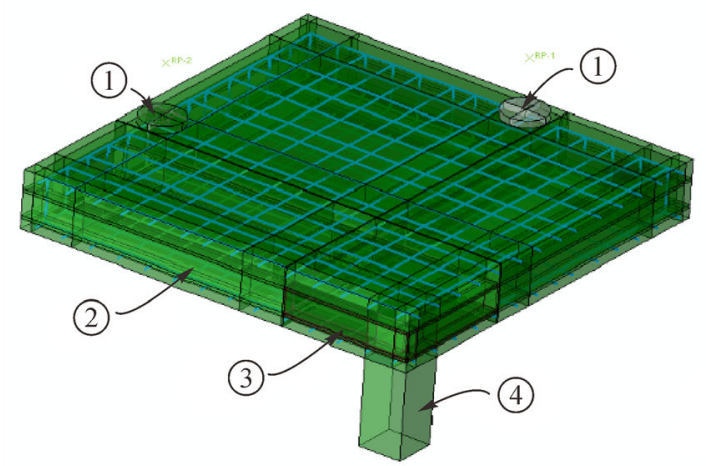

(a)

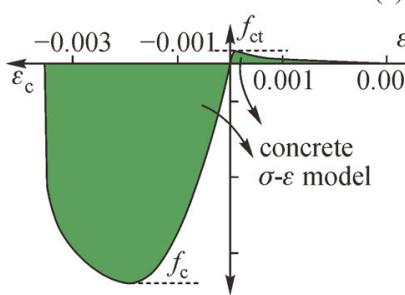

(c)

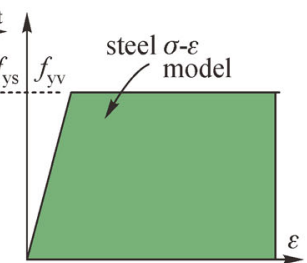

(d)

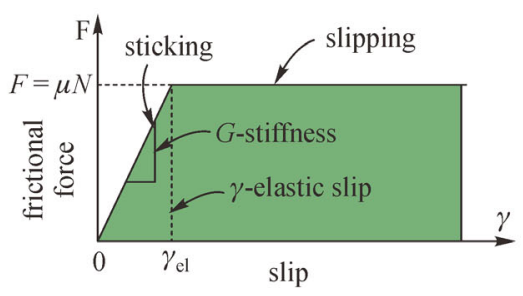

(e)
In CDP, the material dilation angle $\varphi$ is used to represent the stress increase at high confining pressures in the normal-shear stress $p-q$ plane. In RC flat slabs, concrete in the column region is under bi-axial or tri-axial confinement. Hence, for these cases, parameters such as $\varphi$ control the numerical predictions. Figure 4(c) illustrate the numerical response with $\varphi$ varying from $10^{\circ}$ to $55^{\circ}$. As already noted in other studies on RC flat slabs $[23,69,85-$ 87], the most effective response is given for values around $\varphi=40^{\circ}-50^{\circ}$, with an optimal value of $\varphi=48^{\circ}$ employed for the validations described below.

As mentioned above, to model the steel-concrete interface behavior, the contact between the steel profile and the concrete body is modeled using an exponential decay law. In a sensitivity analysis on hybrid RC members provided with shear-heads carried out by authors [690], $\mu$ was varied from low fiction (0.2) to relatively high friction (0.6). For $\mu=0.2$, the load-strain response showed softer behavior in comparison to experimental results, activated by an earlier slip, while $\mu=0.4-0.6$ these were in good agreement with test strain recordings. Hence a friction coefficent $\mu=0.4$ was used in all the analysis described in this paper. It is worth noting that $\mu$ values within the above

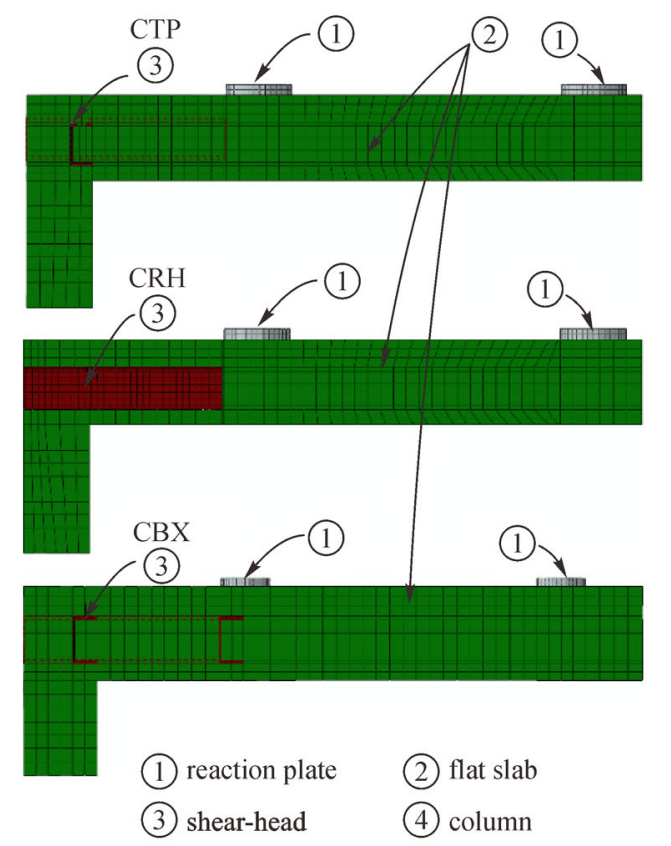

(b)

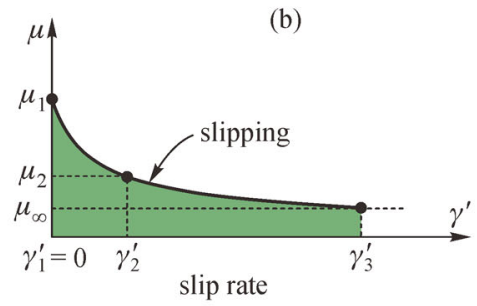

(f)

Fig. 3 Numerical models: (a) typical axisymmetric 3D representation; (b) side view and mesh; (c) uniaxial concrete model; (d) steel model; (e) basic friction model; (f) decay law. 


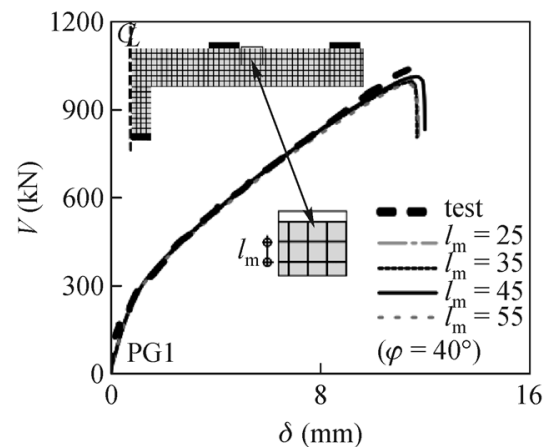

(a)

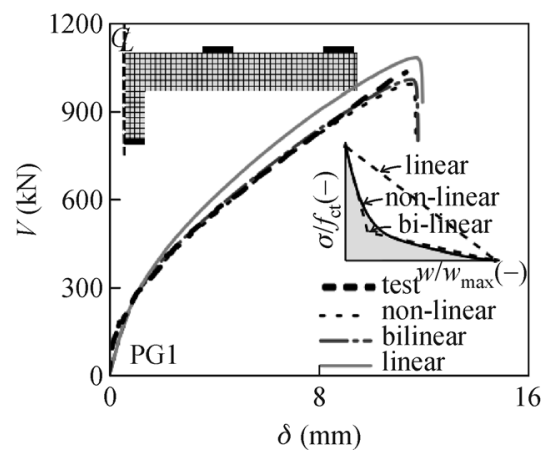

(b)

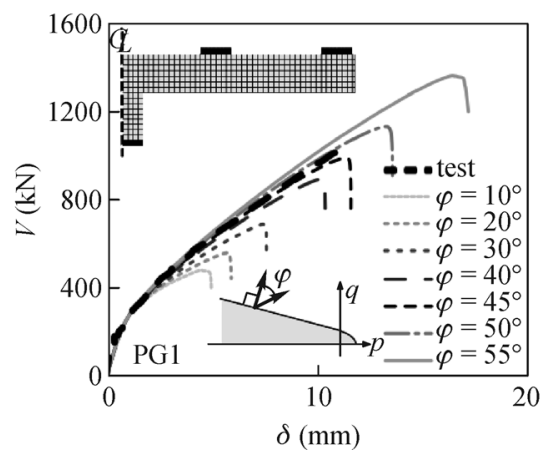

(c)

Fig. 4 Identification of constitutive and numerical parameters for PG1 [81]: (a) mesh size; (b) tension stiffening reponse; (c) dilation angle $\varphi$.

ranges were typically obtained in tests to represent interaction properties between steel profiles and concrete $[88,89]$. The exponential decay function is an extension of the basic Coulomb friction model in which the friction coefficient can be defined as a function of the equivalent slip rate and contact pressure or by specifying the friction coefficient directly (Fig. 3(d)). Additionally, it requires a coefficient for the decay that describes slip response (Fig. 3(f)). In this paper available average test data [89] in terms of shear stress-slip was converted in a friction-slip rate curve as required by the finite element environment, in which $\mu_{1}=0.4$ and $\mu_{\infty}=0.31$.

\subsection{Validation studies}

\subsubsection{Guandalini et al. [81]}

The main aim of the tests was to assess the influence of $\rho_{1}$ $(0.25 \%-1.5 \%)$ and specimen size on the punching shear strength of RC flat slabs without shear reinforcement or shear heads [83]. Double size and half scale members to the Reference Specimen (PG1) were reported (Figs. 2(a)2(c)). The plan dimensions of PG1 were $3 \mathrm{~m} \times 3 \mathrm{~m}$, whereas its thickness was $h=250 \mathrm{~mm}$. The double size specimen (PG3) was $6 \mathrm{~m} \times 6 \mathrm{~m}$ in plan and $500 \mathrm{~mm}$ thick. Half scale specimens (PG6-PG9) were only $1.5 \mathrm{~m} \times 1.5 \mathrm{~m}$ in plan with thickness $h=150 \mathrm{~mm}$. The specimen details and material parameters of the specimens considered herein are summarized in Table 1. For specimens with high $\rho_{1}$ (PG1, PG6, PG7, PG11), failure occurred in punching due to the dislocation of a conical body out of the slab. In two cases, some reinforcement yielded over the column. None of these specimens reached their plastic regime [81].

On the other hand, specimens with low $\rho_{1}$ (PG2b, PG4, PG5, PG8, PG9, PG10) showed clear ductile behavior with a visible plastic plateau. Despite the low $\rho_{\mathrm{l}}$, the double scale specimen PG3, failed in punching shear at a lower load than its flexural strength [81]. Identical failure modes were obtained through the numerical models adopting the procedures described above. In most cases both the elastic and cracked stiffness were accurately predicted, and the ultimate strength was well captured (Table 1 and Fig. 5). The predicted strength of several members with low $\rho_{1}=$ $0.25 \%$ (e.g., PG2b, PG4) was slightly overestimated by about $6 \%$ on average primarily due to the late cracking in the numerical model in comparison with the tests. On the other hand, the ultimate strength of member PG5, also provided with low $\rho_{1}=0.33 \%$, was underestimated with an average $V_{\text {test }} / V_{\mathrm{u}, \text { num }}=1.04$. Additionally, the cracking load of the double-size Specimen PG3 was underestimated by about $30 \%$ leading to a premature development of inelasticity compared to the test. However, there is close agreement in the numerical and test results in terms of the cracked stiffness and the ultimate strength. Specimens with high $\rho_{1}$ (e.g., PG1 and PG6) showed faithful strength predictions with a discrepancy within $3 \%$ from the test values.

\subsubsection{Chana and Birjandi [20] test series}

In this test series, two sets of tests were carried out for the development of a range of structural shear-heads capable of carrying large loads [20]. The first phase involved 16 scaled specimens with or without shear-heads to assess the influence of the shear-head configuration on the ultimate slab behavior. Circular flat slabs (SH series) of $1.55 \mathrm{~m}$ diameter, depicted in Fig. 2(e), were loaded around their perimeter through eight floor ties and supported by 140 $\mathrm{mm}$ square columns, and had a thickness of $120 \mathrm{~mm}$ and two levels of flexural reinforcement $\left(\rho_{1}=0.79 \%\right.$ and $\rho_{1}=$ $1.51 \%$ ). The shear-heads were made of structural channel sections welded in a cruciform or closed-box arrangement. The cruciform shear-heads were made of welded back-toback channel section (CRH) or two pairs of channels around the support region (CTP). On the other hand, closed-box shear-heads (CBX) were made from two pairs of channels which had end beams welded at their outer ends.

The results from the first set of tests enabled the choice of an optimal shear-head configuration, employed further 


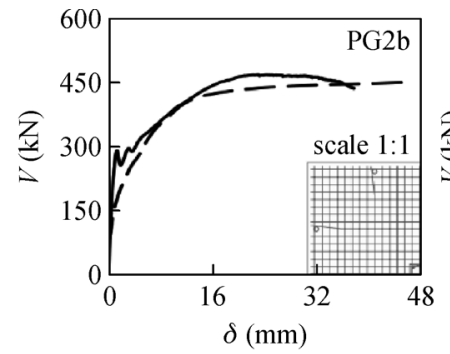

(a)

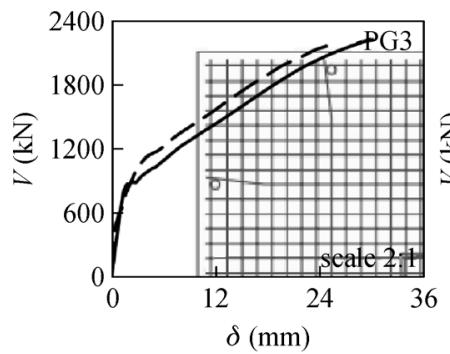

(e)

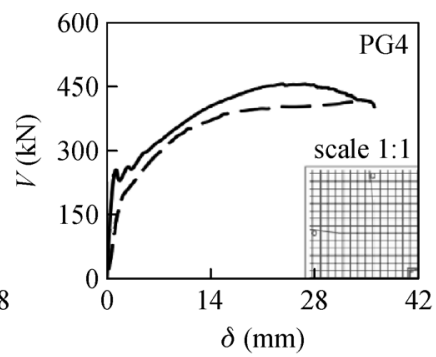

(b)

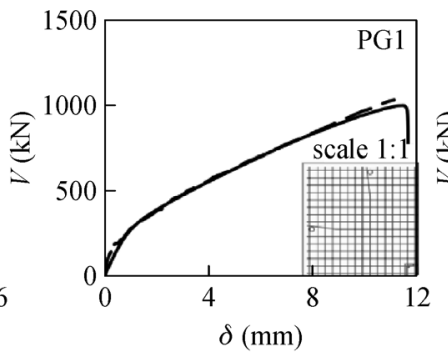

(f)

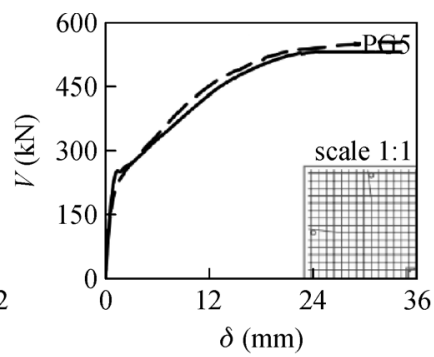

(c)

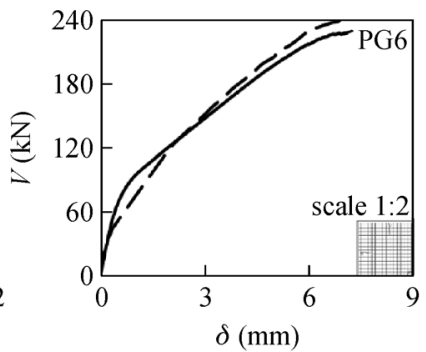

(g)

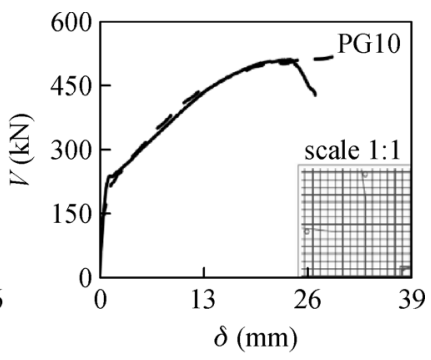

(d)

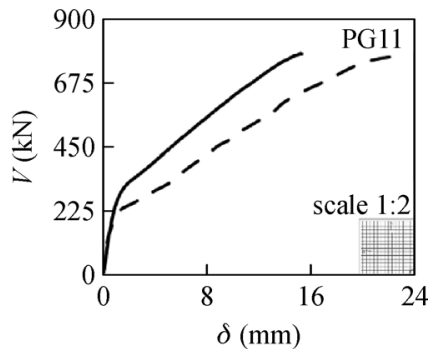

(h)

Fig. 5 Numerical validation: Guandalini et al. test series [47]. (a) PG2b; (b) PG4; (c) PG5; (d) PG10; (e) PG3; (f) PG1; (g) PG6; (h) PG 11 (continuous curves: $V-\delta$ from numerical simulations, while dashed black curves depict $V-\delta$ from tests).

in the second phase which involved tests on $3.0 \mathrm{~m}$ square slabs (FSSH series) of $250 \mathrm{~mm}$ depth supported by 300 $\mathrm{mm}$ wide columns. As illustrated in Fig. 2(f), these were loaded in a similar manner through equally spaced points at $1.2 \mathrm{~m}$ radius from the center of the specimen. All specimens were made of normal concrete with $f_{\mathrm{c}, \text { cube }}=$ 38.1-46.6 MPa. The shear-head dimensions (as indicated in Table 1), were $\mathrm{C} 76 \times 38 \times 7 \mathrm{~mm}$ for the $\mathrm{SH}$ slabs, $\mathrm{C} 127 \times 64 \times 15 \mathrm{~mm}$ for the large-scale slabs with cruciform shear-heads (FSSH2 and FSSH3) and C102 $\times 51 \times 10 \mathrm{~mm}$ for the FSSH4 with closed-box shear-head. The shear-head yield strength was $f_{\mathrm{v}}=355 \mathrm{MPa}$ and the reinforcement yield strength $f_{\mathrm{y}}=500 \mathrm{MPa}$ were considered for modeling, as suggested in the test report [20].

From a total of 20 tests, 13 were reported to develop punching shear failures. The scaled tests with CBX shearheads (SH5 and SH11) showed the highest punching shear capacity characterized by failures outside the shear-head area, followed by the CTP shear-heads (SH2 and SH8). Specimens with shear-head arms placed further than a distance of column size plus half the slab effective depth had columns punching through the slab through the center of the shear-head at lower strengths. The test results showed that shear-heads that produce a larger punching shear perimeter exhibit a larger punching shear capacity with failure surfaces outside or near the edges of the shearheads.

Figure 6 and Table 1 depict the predicted response against the test results as obtained from the test report. The test-to-predicted strength ratio obtained is $V_{\text {test }} / V_{\text {num }}=1.05$ and the coefficient of variation is $6.9 \%$ for the model $\mathrm{SH}$ slabs, and $V_{\text {test }} / V_{\text {num }}=1.02$ and COV of $7.7 \%$ for the large scale FSSH slabs. Both the stiffness and ultimate capacity of the specimens with shear-heads are well predicted $(\rho=$ $0.79 \%$ for $\mathrm{SH} 2, \mathrm{SH} 3, \mathrm{SH} 5 ; \rho=1.51 \%$ for $\mathrm{SH} 8$, SH9, SH11; $\rho=1.00 \%$ for FSSH2, FSSH3 and FSSH4), offering confidence in the numerical procedures employed. For members without shear-heads (SH1, SH7, and FSSH1), although the cracked stiffness is stiffer compared to the tests, $V_{\text {test }} / V_{\text {num }}=1.01$ and the failure mode is correctly predicted.

The tension damage scalar maps are depicted in Figs. 7(a)-7(d) for model tests with shear-heads and $\rho=$ $0.79 \%$ (SH2, SH3, SH5) and for the corresponding slab without shear-heads (SH1) that failed in punching. These show that the top crack patterns are governed by flexural cracking with cracks extending to the slab edge while, regardless the shear-head type, the punching shear crack initiates from the bottom tip of the shear-head arm and extends through the flexural reinforcement to the tension face of the slab. This suggests a force transfer through the shear-head bottom-flange supported struts, similar to the case of Specimen SH1 without shear-head in Fig. 7(d) in which the strut is supported at the column-slab connection.

In terms of shear-head behavior, Fig. 7 shows that the cruciform shear-heads ( $\mathrm{SH} 2$ and $\mathrm{SH} 3$ ) developed some yielding at the top flange, while the closed-box shear-head (SH5) was well below the yield stress. These stress levels are combined with stronger tension damage for SH5 as evident in the $3 \mathrm{D}$ representations around the shear-head region. This indicates higher reinforcement stresses above the shear-head that are correlated to a shift in the weak bending section at the shear-head tip. Similarly, for slabs with cruciform shear-heads ( $\mathrm{SH} 2$ and $\mathrm{SH} 3$ ), the highest 


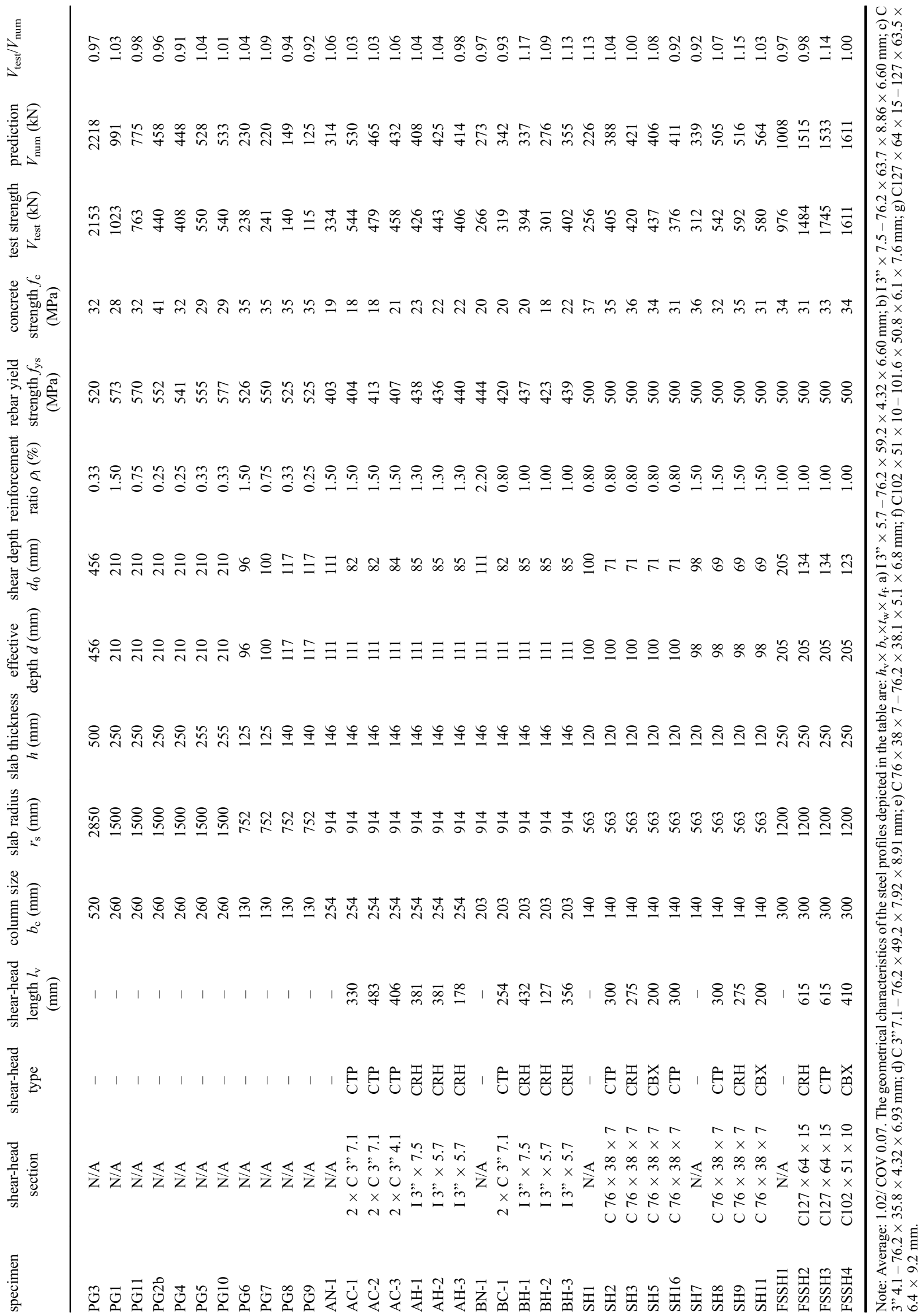




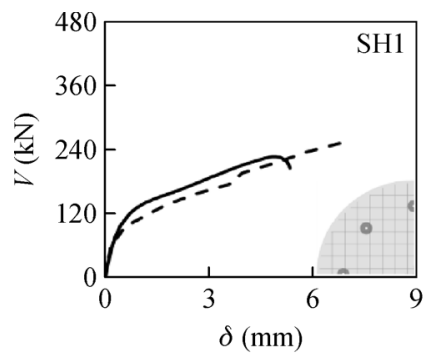

(a)

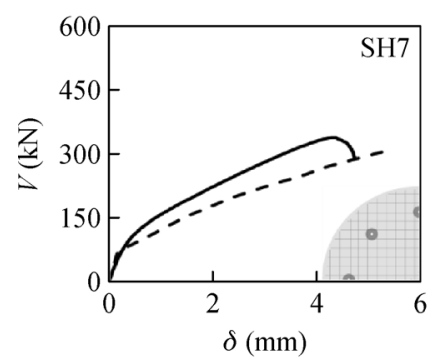

(e)

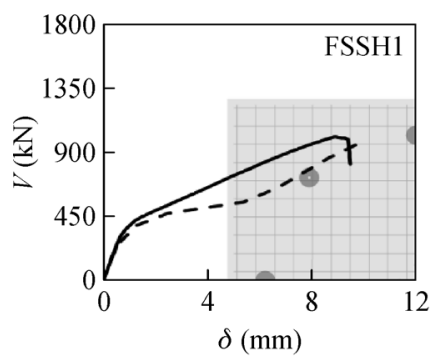

(i)

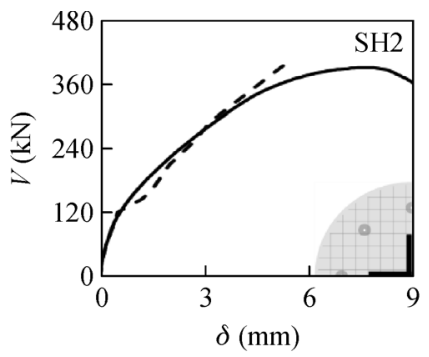

(b)

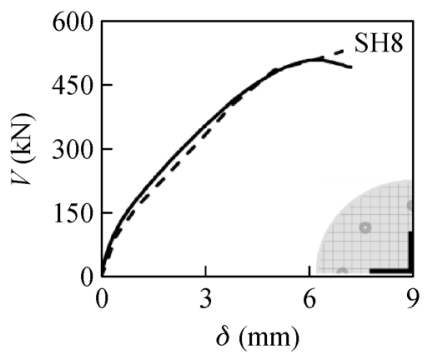

(f)

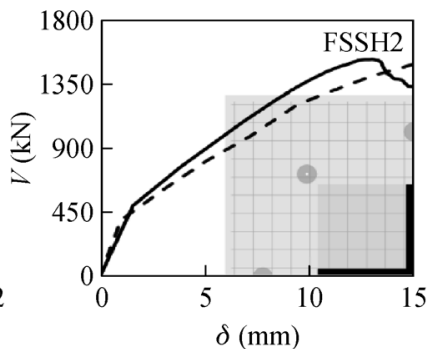

(j)

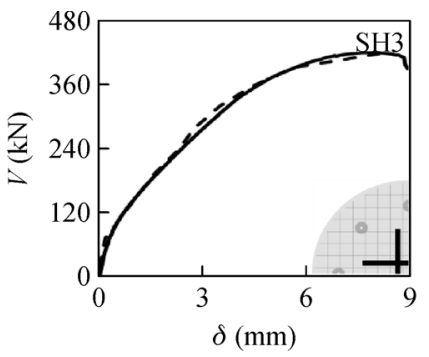

(c)

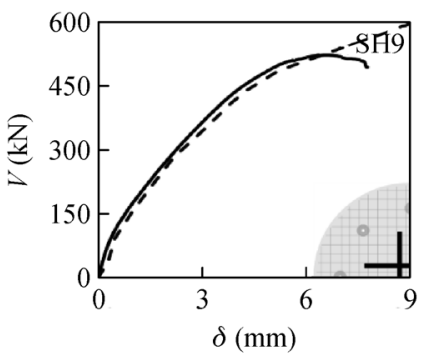

(g)

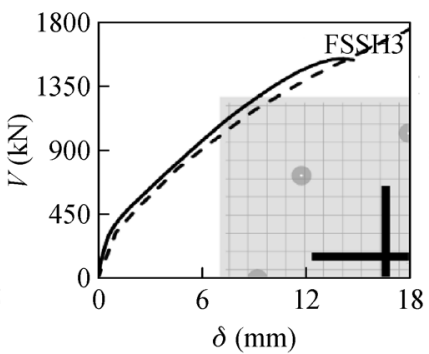

(k)

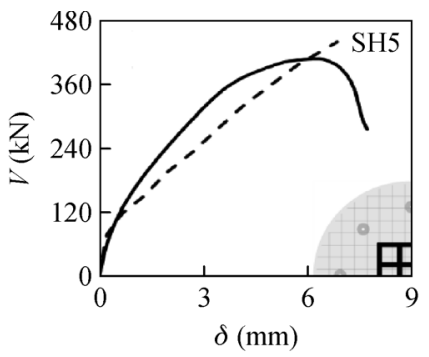

(d)

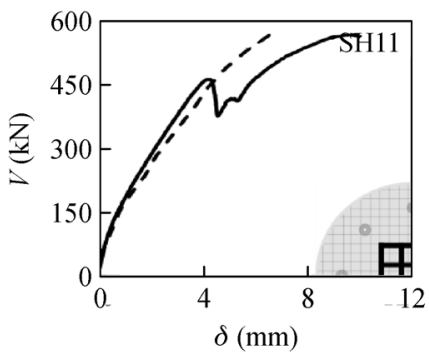

(h)

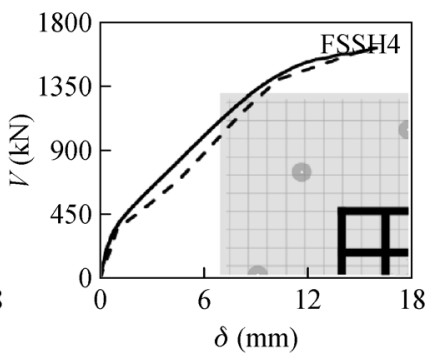

(1)

Fig. 6 Numerical validations: Chana and Birjandi test series [20]. (a) SH1; (b) SH2; (c) SH3; (d) SH5; (e) SH7; (f) SH8; (g) SH0; (h) SH11; (i) FSSH1; (j) FSSH2; (k) FSSH3; (1) FSSH4 (continuous black curves represent the $V$ - $\delta$ from numerical simulations, while dashed black curves depict $V-\delta$ from tests).

flexural damage is outside of the shear-heads indicating an influence from the shear-head on moment distribution, while for SH1 it occurs at the symmetry line following the weak bending axis. These observations indicate that the weak section, both in terms of flexure and punching shear, is translated away from the column face, outside of the shear-head region.

\subsubsection{Hawkins and Corley [7] test series}

In this test series, 20 -one $2.1 \mathrm{~m} \times 2.1 \mathrm{~m}$ square $146 \mathrm{~mm}$ thick flat slab specimens with reinforcement ratios between 1.8 and $3.3 \%$ and $45^{\circ}$ cut cruciform shear-heads, supported on square columns with sides of $254 \mathrm{~mm}$ or $204 \mathrm{~mm}$, were loaded symmetrically at the edges of the slab [6]. Cruciform shear-heads made either from Standard American I-sections (I 3" $\times 7.5$ or I 3 " $\times 5.7$ equivalent of I 76.2 $\mathrm{mm} \times 11.2 \mathrm{~kg} / \mathrm{m}$ or I $76.2 \mathrm{~mm} \times 8.48 \mathrm{~kg} / \mathrm{m}$, respectively) or two pairs of channels $(2 \times \mathrm{C} 3$ " 7.1 or $2 \times \mathrm{C} 3$ " 4.1 equivalent of $2 \times \mathrm{C} 76.2 \mathrm{~mm} 10.6 \mathrm{~kg} / \mathrm{m}$ or $2 \times \mathrm{C} 76.2 \mathrm{~mm}$
$6.10 \mathrm{~kg} / \mathrm{m}$, respectively) running above the columns, were fully embedded in normal or lightweight concrete flat slab. The reported concrete strength of the slabs varied between $f_{\mathrm{c}}=18.1-22.8 \mathrm{MPa}$, while the flexural reinforcement had $f_{\mathrm{ys}}=403-444 \mathrm{MPa}$ (Table 1). The shear-head yield strength was assumed as $f_{\mathrm{v}}=300 \mathrm{MPa}$ based on an average obtained from tests employing similar configurations as reported by the same authors in a companion study on edge connections [7].

Reference specimens (AN-1 and BN-1) without shearheads failed in punching with the failure surface extending from the column-slab compression face intersection to the tension face of the slab at inclinations between $\theta=20^{\circ}$ $30^{\circ}$. For slabs with relatively stiff shear-heads, the failure surface generally followed the perimeter of the shear-head with $\theta=20^{\circ}-45^{\circ}$, while for members with relatively flexible shear-heads, the failure surface developed inside the shear-head with inclinations of about $\theta=30^{\circ}$. The results indicated two distinct responses, depending on the stress state of the shear-head. For elastic shear-head behavior, the failure surface initiated from its tip. For 


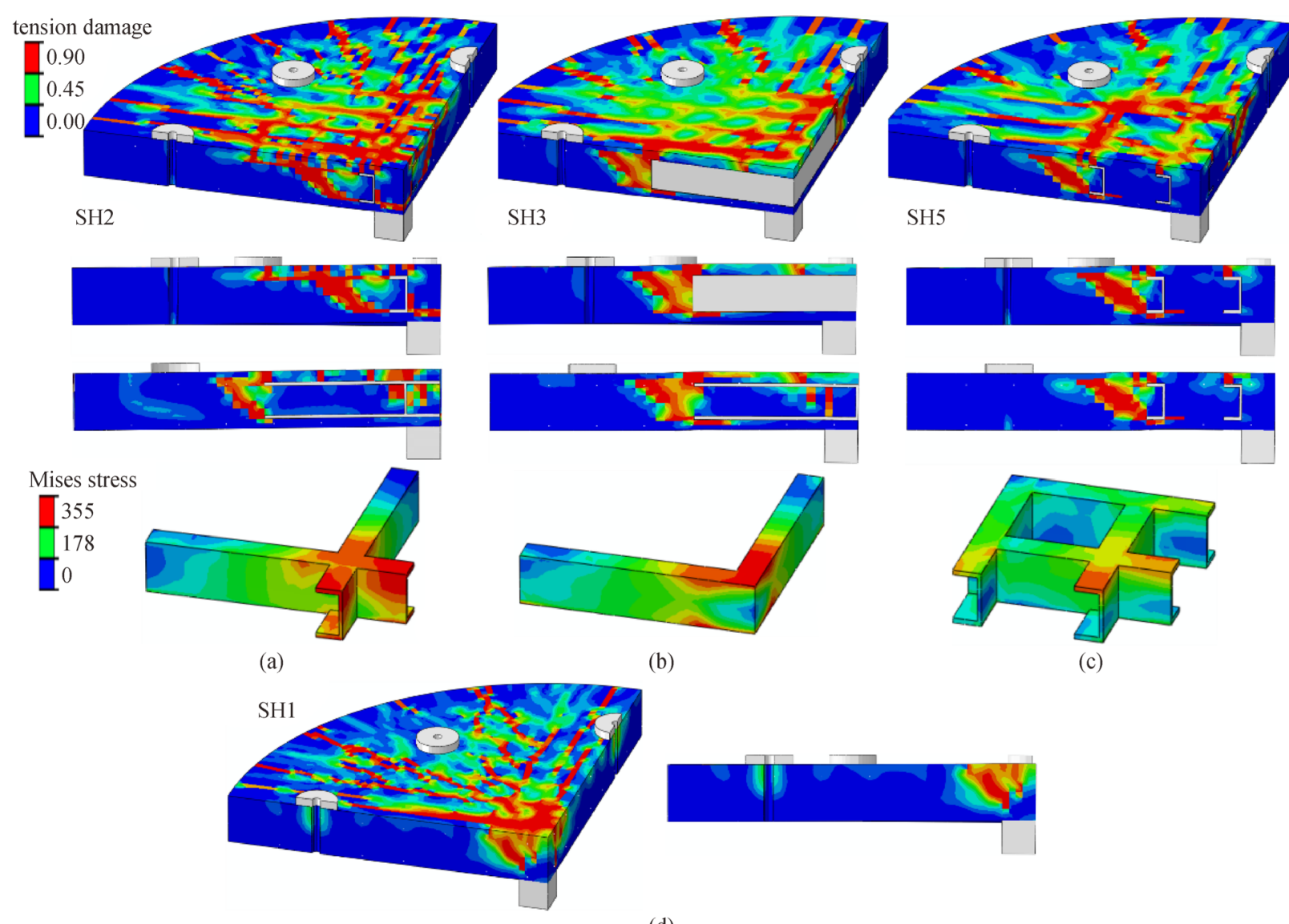

(d)

Fig. 7 Tension damage patterns for slabs with and without shear-heads, and stresses in shear-heads for Specimens: (a) SH2; (b) SH3; (c) $\mathrm{SH} 5$; (d) SH1.

cases where yielding occurred, a more flexible response was observed with the failure surface crossing the shearhead within $25 \%$ of its length from the edge.

The $V-\delta$ response obtained from the numerical simulations for the specimens with or without shear-heads are illustrated in Fig. 8, while the main parameters are given in Table 1. Good agreement was obtained between the predictions and test strengths with a $V_{\text {test }} / V_{\text {num }}=1.05$ and coefficient of variation $\mathrm{COV}$ of $6.3 \%$. Although a coarser mesh $\left(l_{\mathrm{m}}=h / 7\right)$ was used for these models to reduce the computational time in comparison to $\mathrm{SH}$ and FSSH specimens (with $l_{\mathrm{m}}=h / 10$ ), both the predicted strengths and tension damage patterns offer a clear insight into the governing ultimate behavior. The $V-\delta$ plots show mostly sudden drops in capacity after reaching ultimate, while the crack patterns at the quarter slab symmetry line in Fig. 9 clearly depicts inclined damage tension fields, outside of the shear-head tip, suggesting punching shear failures. Along its section size, the embedment length of the shear-head plays a significant role in the ultimate slab response as it determines the location of the failure surface.

Overall, the deformational response and failure modes obtained from the numerical simulations were in good agreement with reported tests results. The top face and cross-section damage patterns obtained from the analysis resemble the top crack patterns and punching shear failures obtained from tests. Having gained confidence in the numerical procedures employed in this investigation through the validations of the test results from 36 specimens of which 20 were provided with a wide range of shear-heads, the following section describes parametric assessments which were carried out in order to provide more detailed insights into the behavior of RC slabs with shear-heads.

\section{Parametric assessments}

The tests modeled in Section 2.2 focused on the response of relatively thin flat slabs with shear-heads, having an effective depth varying in the range $d=98-111 \mathrm{~mm}(h=$ $120-146 \mathrm{~mm}$ ). From the 20 specimens with shear-heads simulated, only 3 had practical slab effective depths with $d$ $=205 \mathrm{~mm}(h=250 \mathrm{~mm})$. Also, these slabs were provided with shear-head length-to-depth ratios of $l_{\mathrm{v}} / h_{\mathrm{v}}=1.33-6.33$, reinforcement ratios of $\rho_{1}=0.5 \%-1.5 \%$ and concrete strengths $f_{\mathrm{c}}=16.7-36.2 \mathrm{MPa}$. Although these experimental studies may appear to cover a wide range of $l_{\mathrm{v}} / h_{\mathrm{v}}$, 


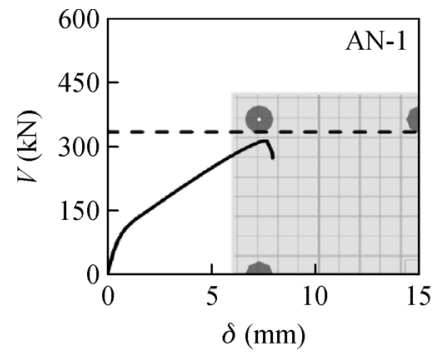

(a)

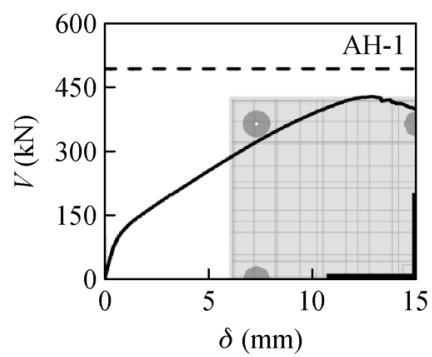

(e)

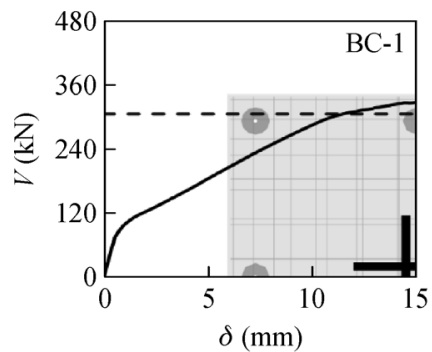

(i)

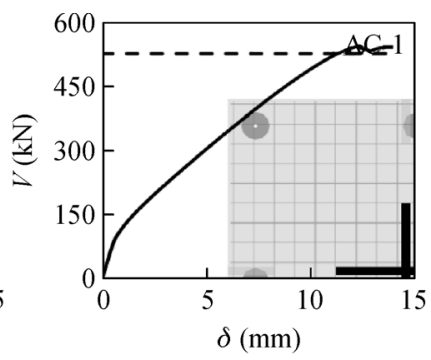

(b)

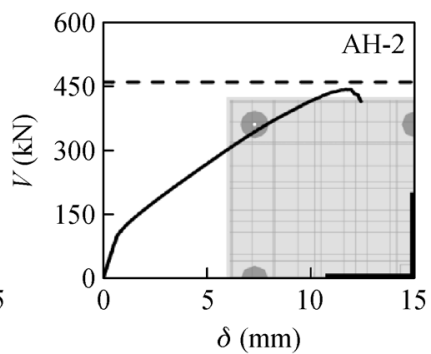

(f)

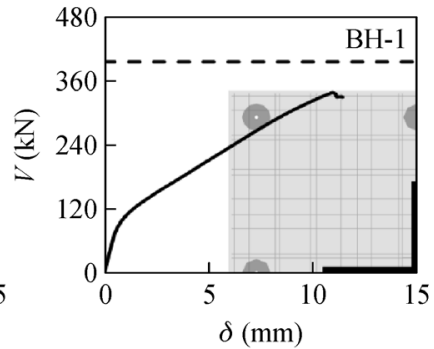

(j)

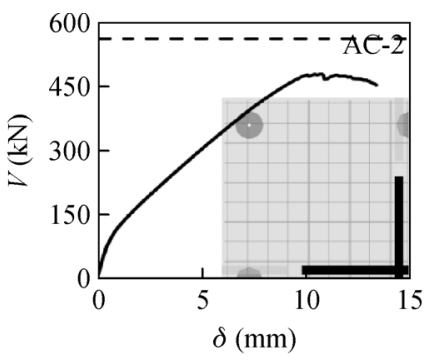

(c)

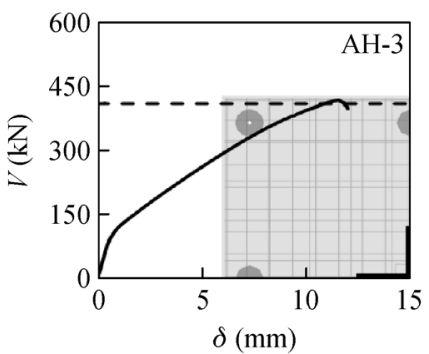

(g)

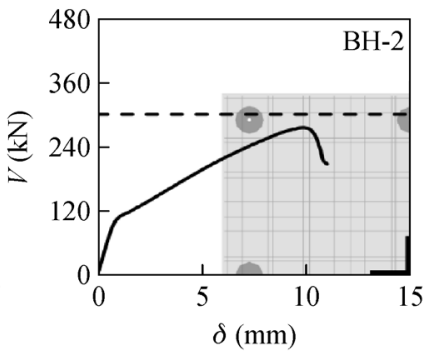

(k)

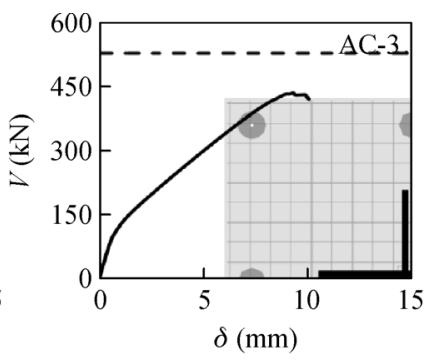

(d)

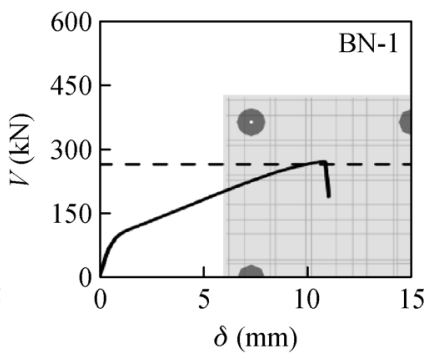

(h)

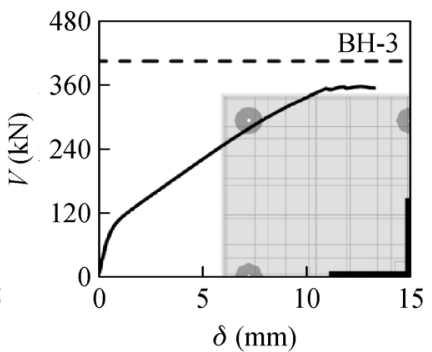

(1)

Fig. 8 Numerical validations for Corley and Hawkins test series [6]: (a) AN-1; (b) AC-1; (c) AC-2; (d) AC-3; (e) AH-1; (f) AH-2; (g) AH-3; (h) BN-1; (i) BC-1; (j) BH-1; (k) BH-2; (1) BH-3 (continuous black curves represent the $V$ - $\delta$ from numerical simulations, while dashed black curves depict $V-\delta$ from tests).

$\rho_{\mathrm{l}}, f_{\mathrm{c}}$, slab spans and depths, only FSSH specimens (e.g., $d=205 \mathrm{~mm}$ ) can be considered within practical ranges. Existing assessment models are similarly based on a limited number of test ranges, and their reliability is therefore limited to these ranges. Parametric investigations covering parameters outside of the available test ranges are therefore required to provide improved assessment models with wider applicability.

A total of 122 three-dimensional models, including 44 CTP, $44 \mathrm{CRH}$, and $34 \mathrm{CBX}$ shear-heads, were constructed using the numerical procedures described in Section 2.1, in which RC flat slabs were connected to RC columns by means of full-embedded shear-heads. The parametric investigations were undertaken to provide detailed insights into the behavior of a wide range of configurations outside of the existing test database, hence enabling a direct assessment in terms of strength and deformation characteristics, and to provide offer a wider data set for developing practical analytical models. The nonlinear parametric assessments may be grouped into five main studies in which the following key parameters were investigated:
1) Shear-head embedment length-to-depth ratio $\left(l_{\mathrm{v}} / h_{\mathrm{v}}=\right.$ $0.5-5.0)$ : in each case, the reinforcement ratio $\rho_{1}$ was varied from $0.31 \%$ to $1.54 \%$. All other parameters were kept constant including the effective depth d, slab radius $r_{\mathrm{s}}$, concrete strength $f_{\mathrm{c}}$ and shear-head section size $\left(h_{\mathrm{v}} \times b_{\mathrm{v}} \times\right.$ $t_{\mathrm{w}} \times t_{\mathrm{f}}=100 \mathrm{~mm} \times 100 \mathrm{~mm} \times 6 \mathrm{~mm} \times 10 \mathrm{~mm}$, for CRH shear-heads; total $h_{\mathrm{v}} \times b_{\mathrm{v}}=100 \mathrm{~mm} \times 100 \mathrm{~mm}$ from two parallel flange channel sections (C) $100 \mathrm{~mm} \times 50 \mathrm{~mm} \times$ $10 \mathrm{~mm}$ for CTP; total $h_{\mathrm{v}} \times b_{\mathrm{v}}=100 \mathrm{~mm} \times 200 \mathrm{~mm}$ from four C $100 \mathrm{~mm} \times 50 \mathrm{~mm} \times 10 \mathrm{~mm}$ for CBX)

2) Slab radius $\left(r_{\mathrm{s}} / d=5.4-11.8\right)$ : in conjunction with $\rho_{1}=$ $0.65 \%-1.05 \%$, and a constant $l_{\mathrm{v}}, d, f_{\mathrm{c}}, r_{\mathrm{s}} / d$, and $h_{\mathrm{v}} \times b_{\mathrm{v}}$.

3) Slab bending effective depth $(d=170-370 \mathrm{~mm})$ : in conjunction with $\rho_{1}=0.42 \%-1.18 \%$ with constant $l_{\mathrm{v}} / h_{\mathrm{v}}, f_{\mathrm{c}}$, $r_{\mathrm{s}}$, and $h_{\mathrm{v}} \times b_{\mathrm{v}}$

4) Shear-head section size with varying $h_{\mathrm{v}} \times b_{\mathrm{v}}$ for $l_{\mathrm{v}} / h_{\mathrm{v}}$ $=1.0$ and 3.0, and constant $f_{\mathrm{c}}, r_{\mathrm{s}}, d$.

$h_{\mathrm{v}} \times b_{\mathrm{v}} \times t_{\mathrm{w}} \times t_{\mathrm{f}}=100 \mathrm{~mm} \times 100 \mathrm{~mm} \times 6 \mathrm{~mm} \times$ $10 \mathrm{~mm}, 160 \mathrm{~mm} \times 160 \mathrm{~mm} \times 8 \mathrm{~mm} \times 13 \mathrm{~mm}, 200 \mathrm{~mm} \times$ $200 \mathrm{~mm} \times 9 \mathrm{~mm} \times 15 \mathrm{~mm}$, referred to as CRH100, CRH160, CRH200, respectively;

$h_{\mathrm{v}} \times b_{\mathrm{v}}=100 \mathrm{~mm} \times 100 \mathrm{~mm}, 150 \mathrm{~mm} \times 150 \mathrm{~mm}$, 


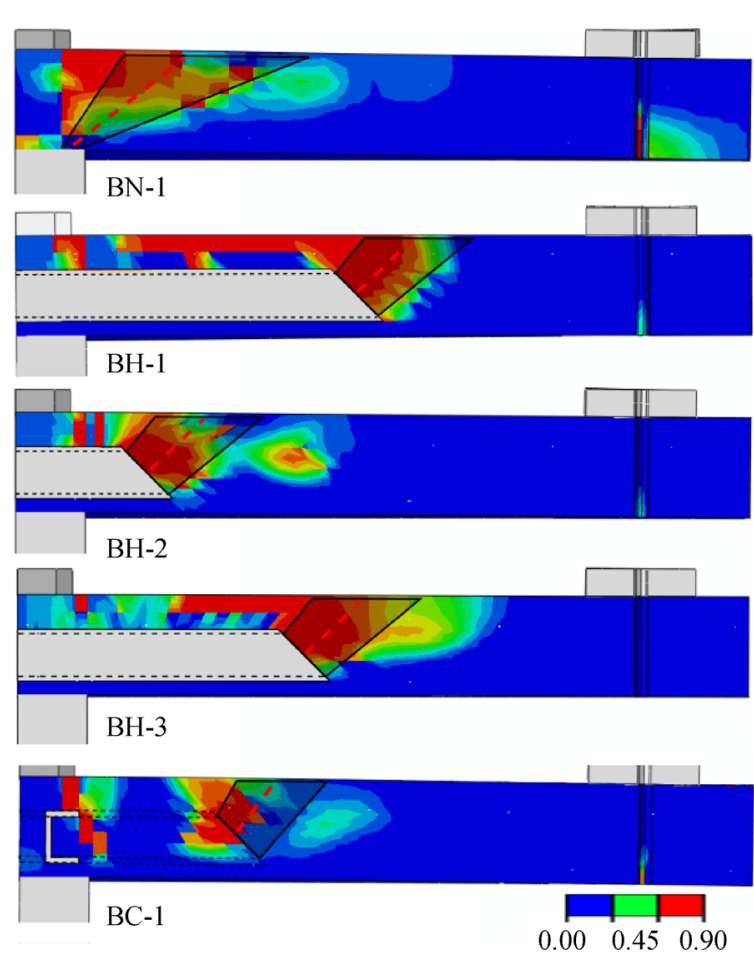

Fig. 9 Influence of the embedment length on the tension damage and compression fields.

$200 \mathrm{~mm} \times 150 \mathrm{~mm}$ from two C $100 \mathrm{~mm} \times 50 \mathrm{~mm} \times$ $10 \mathrm{~mm}$, C $150 \mathrm{~mm} \times 75 \mathrm{~mm} \times 18 \mathrm{~mm}$, PFC $200 \mathrm{~mm} \times$ $75 \mathrm{~mm} \times 23 \mathrm{~mm}$, respectively, for CTP;

$h_{\mathrm{v}} \times b_{\mathrm{v}}=100 \mathrm{~mm} \times 200 \mathrm{~mm}, 150 \mathrm{~mm} \times 350 \mathrm{~mm}$, $200 \mathrm{~mm} \times 350 \mathrm{~mm}$ from four C $100 \mathrm{~mm} \times 50 \mathrm{~mm} \times$ $10 \mathrm{~mm}$, C $150 \mathrm{~mm} \times 75 \mathrm{~mm} \times 18 \mathrm{~mm}$, PFC $200 \mathrm{~mm} \times$ $75 \mathrm{~mm} \times 23 \mathrm{~mm}$, respectively, for CBX.

5) Concrete strength $f_{\mathrm{c}}=30$ and $50 \mathrm{MPa}$ and $\rho_{1}=$ $0.63 \%-0.98 \%$, with constant $l_{\mathrm{v}} / h_{\mathrm{v}}, d, r_{\mathrm{s}}$ and shear-head section size.

Selected results from the parametric assessments are plotted in Figs. 10-13 in terms of rotational response $(V-\psi)$ or characteristics values at ultimate, in which the load $V$ is normalized against the control perimeter $b_{0}$ and concrete strength $f_{\mathrm{c}}$, as described in Eqs. (1) and (2) and illustrated in Fig. 14. For CRH, $b_{0}$ is defined for each shear-head by an arc-length with a radius equal to the in-plane half strut projection $d_{0} / 2$ plus connecting lines (Fig. 14(b)). As illustrated in Fig. 14(c), the shape of the critical perimeter for CTP shear-heads follows the same configuration, considering the distance between the steel profiles. It is worth noting, that Eqs. (1a)-(1c) are limited to shear-head lengths for which the control perimeter does not lie within $d_{0} / 2$ from the column face. Hence, for short shear-heads, $b_{0}$ should be constructed by accounting for the column, noting that $b_{0}$ can be evaluated using Eqs. (1a)-(1b) for straight-cut CRH and CTP shear-heads, respectively.

For CBX shear-heads, the critical perimeter is located at $d_{0} / 2$ from the edge of the bottom flange, throughout the length of all shear-head sides considering rounded corners (Fig. 14(d)). The length of a CBX critical perimeter can be assessed using Eq. (1c). It is worth noting that the cut type of the shear-head influences the location of the geometry of the force transfer mechanism. Hence, for shear-heads that have a $45^{\circ}$ cut [6] (Fig. 9), the critical perimeter reduces with due account for the location of the force transferring strut that tends to form closer to the root of the shear-head, in comparison to the case of straight-cut shear-heads. In a simplified manner, $l_{\mathrm{v}}$ should be reduced with $h_{\mathrm{v}} / 2$ in Eqs. (1a)-(1b).

Besides the obtained $V-\psi$, Figs. 10 to 12 indicate the failure criteria (FC) for punching shear in RC flat slabs (Eq. (3) [90]) that accounts for a shear-head dependent support of the governing strut, and provide key observations on the member behavior. These include envelopes of the loads corresponding to yielding in the steel reinforcing materials, namely: longitudinal reinforcement (RY), flange of shear-head (FY), web of shear-head (WY), and the ultimate envelope (U). In the case of RY, the points on the graph correspond to the initiation of yielding in one truss element in the analysis. For FY and WY, they correspond to the case in which yielding spreads in a band (i.e., at least two mesh elements for FY, typically at the edges of the flanges; or a band of mesh elements in which WY occurs from the top to bottom flange).

$$
b_{0, \mathrm{CTP}}=4\left[\left(l_{v}+\frac{d_{0} \sqrt{2}}{2} \sin \frac{\pi}{8}\right) \sqrt{2}+\left(2 b_{\mathrm{v}}+a\right)+\frac{\pi d_{0}}{8}\right] \text { for CTP, }
$$

$$
\begin{gathered}
b_{0, \mathrm{CRH}}=4\left[\left(\frac{b_{\mathrm{c}}}{2}+l_{\mathrm{v}}+\frac{d_{0} \sqrt{2}}{2} \sin \frac{\pi}{8}\right) \sqrt{2}+\frac{\pi d_{0}}{8}\right] \text { for } \\
b_{0, \mathrm{CBX}}=4\left[2 l_{\mathrm{v}}+\left(2 b_{\mathrm{v}}+a\right)+\frac{\pi d_{0}}{4}\right] \text { for } \mathrm{CBX}, \\
d_{0}=d-d_{\mathrm{vfb}}-t_{f} / 2, \\
k_{\psi}=0.75 /\left[1+15 \cdot \psi \cdot d_{0} /\left(d_{\mathrm{g} 0}+d_{\mathrm{g}}\right)\right] .
\end{gathered}
$$

\subsection{Shear-head embedment length}

Figures 10(a)-10(e) illustrate the rotational response $V-\psi$ from selected CTP, CRH, and CBX numerical models in which the embedment length $l_{\mathrm{v}}$ was varied against the flexural reinforcement ratio $\rho_{1}$. For low to intermediate reinforcement ratios $\left(\rho_{1}=0.3 \%-0.9 \%\right)$, regardless of the embedment length and shear-head type, yielding of the longitudinal reinforcement bars (RY) triggers the failure, with a more pronounced effect for low $\rho_{1}$ combined with low $l_{\mathrm{v}} / h_{\mathrm{v}}$. For shear-head length ratios $l_{\mathrm{v}} / h_{\mathrm{v}} \leqslant 2.0$ 


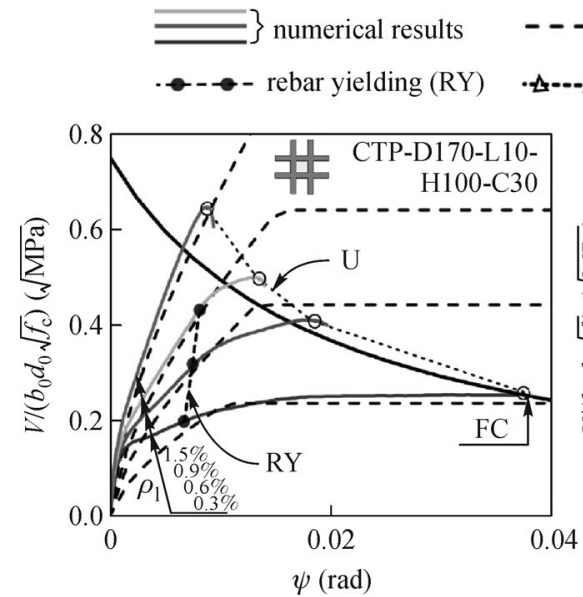

(a)

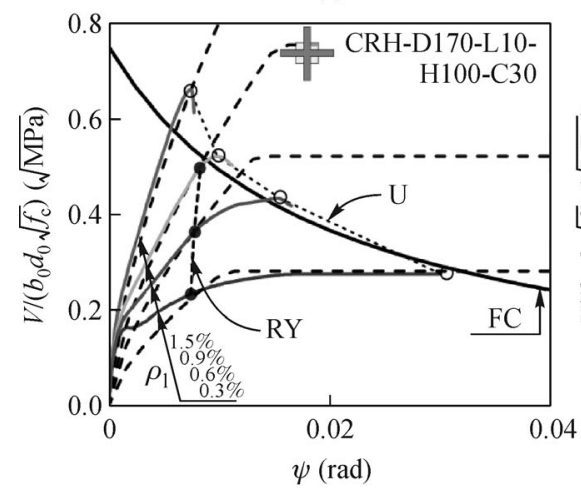

(d)

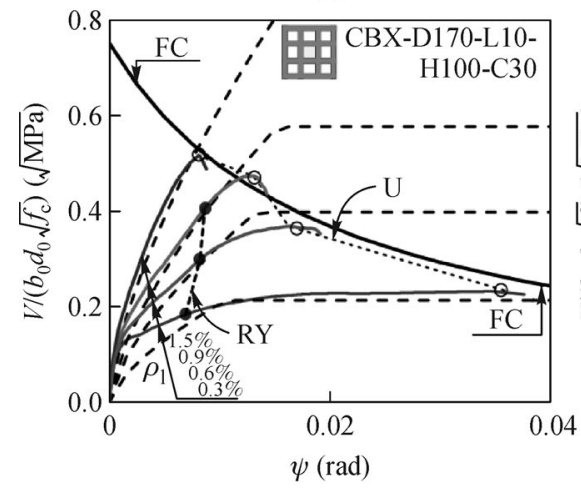

(g)

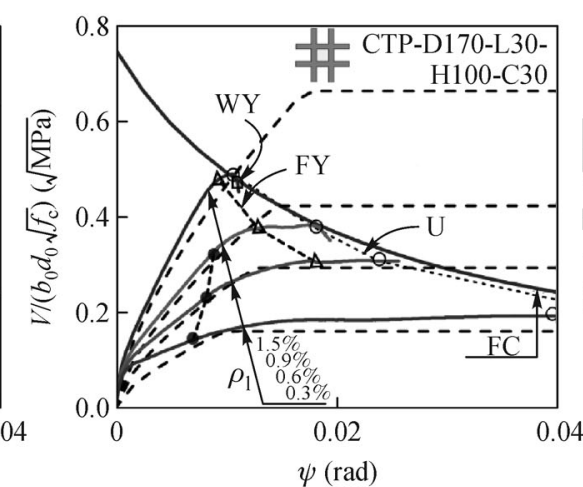

(b)

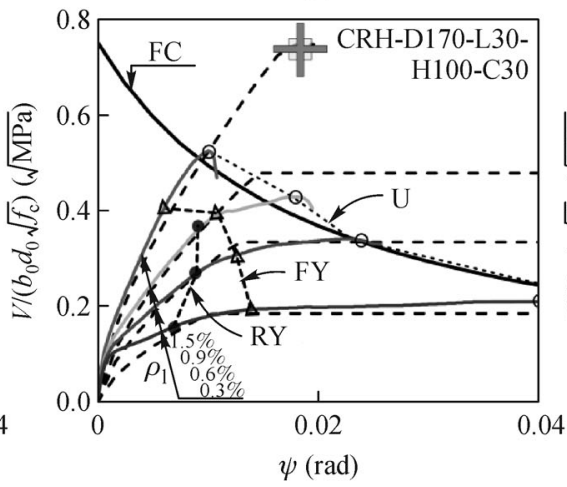

(e)

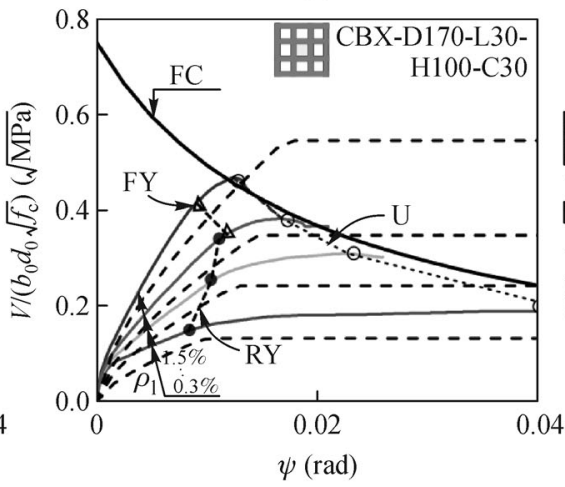

(h)

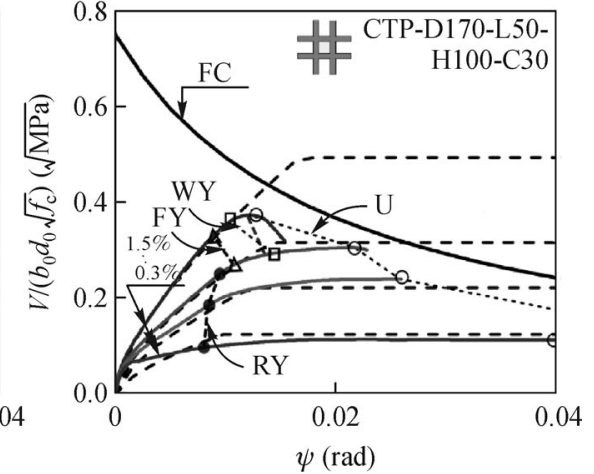

(c)

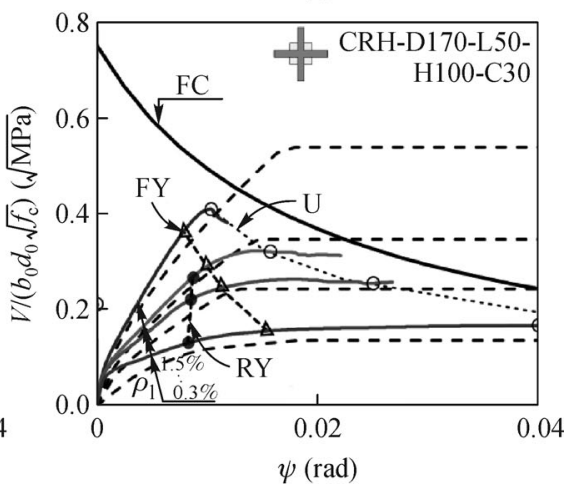

(f)

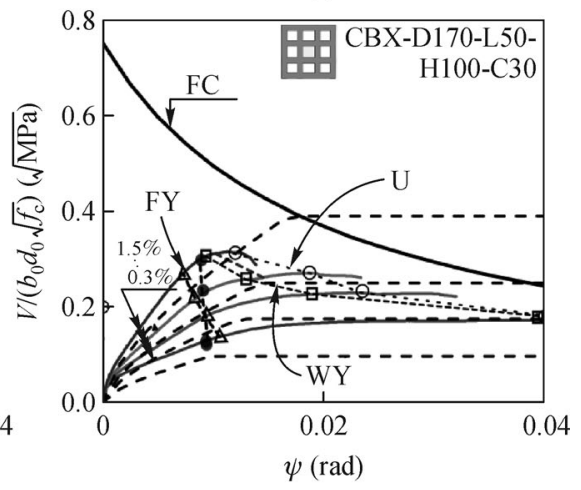

(i)

Fig. 10 Influence of the embedment length and reinforcement ratio on the slab capacity and rotation: (a) CTP, $d=170 \mathrm{~mm}, h_{\mathrm{v}}=100 \mathrm{~mm}$, $l_{\mathrm{v}} / h_{\mathrm{v}}=1.0, f_{\mathrm{c}}=30 \mathrm{MPa}$; (b) CTP, $d=170 \mathrm{~mm}, h_{\mathrm{v}}=100 \mathrm{~mm}, l_{\mathrm{v}} / h_{\mathrm{v}}=3.0, f_{\mathrm{c}}=30 \mathrm{MPa}$; (c) CTP, $d=170 \mathrm{~mm}, h_{\mathrm{v}}=100 \mathrm{~mm}, l_{\mathrm{v}} / h_{\mathrm{v}}=5.0, f_{\mathrm{c}}=$ $30 \mathrm{MPa}$; (d) CRH, $d=170 \mathrm{~mm}, h_{\mathrm{v}}=100 \mathrm{~mm}, l_{\mathrm{v}} / h_{\mathrm{v}}=1.0, f_{\mathrm{c}}=30 \mathrm{MPa}$; (e) CRH, $d=170 \mathrm{~mm}, h_{\mathrm{v}}=100 \mathrm{~mm}, l_{\mathrm{v}} / h_{\mathrm{v}}=3.0, f_{\mathrm{c}}=30 \mathrm{MPa}$; (f) CRH, $d=170 \mathrm{~mm}, h_{\mathrm{v}}=100 \mathrm{~mm}, l_{\mathrm{v}} / h_{\mathrm{v}}=5.0, f_{\mathrm{c}}=30 \mathrm{MPa}$; (g) CBX, $d=170 \mathrm{~mm}, h_{\mathrm{v}}=100 \mathrm{~mm}, l_{\mathrm{v}} / h_{\mathrm{v}}=1.0, f_{\mathrm{c}}=30 \mathrm{MPa}$; (h) CBX, $d=$ $170 \mathrm{~mm}, h_{\mathrm{v}}=100 \mathrm{~mm}, l_{\mathrm{v}} / h_{\mathrm{v}}=2.0, f_{\mathrm{c}}=30 \mathrm{MPa}$; (i) CBX, $d=170 \mathrm{~mm}, h_{\mathrm{v}}=100 \mathrm{~mm}, l_{\mathrm{v}} / h_{\mathrm{v}}=5.0, f_{\mathrm{c}}=30 \mathrm{MPa}$.

$\left(l_{\mathrm{v}} / r_{\mathrm{s}} \leqslant 0.15\right)$ the shear-head remains largely elastic. As $l_{\mathrm{v}}$ increases, inelastic strains develop at the shear-head flange edges (FY). For $l_{\mathrm{v}} / h_{\mathrm{v}} \geqslant 3.0\left(l_{\mathrm{v}} / r_{\mathrm{s}} \geqslant 0.22\right)$ and $\rho_{1}=0.9 \%$, (FY) is triggered immediately after (RY). For intermediate CRH shear-head lengths $\left(l_{\mathrm{v}} / h_{\mathrm{v}}=2.0-3.0 ; l_{\mathrm{v}} / r_{\mathrm{s}}=0.15-\right.$ 0.22 ) some yielding at the bottom flange due to strut support was observed. As depicted in Figs. 10(f)-10(i), for relatively long CRH and CBX shear-heads $\left(l_{\mathrm{v}} / h_{\mathrm{v}}=5.0\right.$; $\left.l_{\mathrm{v}} / r_{\mathrm{s}}=0.36\right)$ and relatively high $\rho_{\mathrm{l}}=0.9 \%-1.5 \%$ ), flange yielding (FY) is accompanied by web yielding (WY), resulting in full yielding of the shear-head cross-section.

As illustrated in Fig. 11 compared to Fig. 12, an increase in slab radius from $r_{\mathrm{s}} / d=8.18\left(r_{\mathrm{s}}=1390 \mathrm{~mm}\right)$ to $r_{\mathrm{s}} / d=$ $11.76\left(r_{\mathrm{s}}=2000 \mathrm{~mm}\right)$, for constant $l_{\mathrm{v}} / h_{\mathrm{v}}=1.0$ and $3.0 \mathrm{~mm}$ 


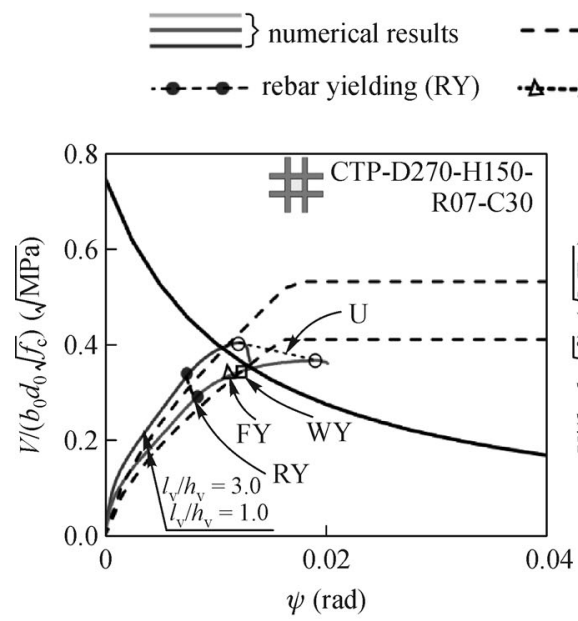

(a)

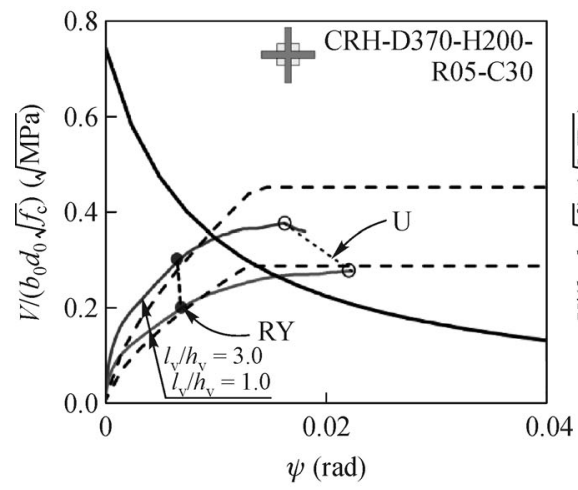

(d)

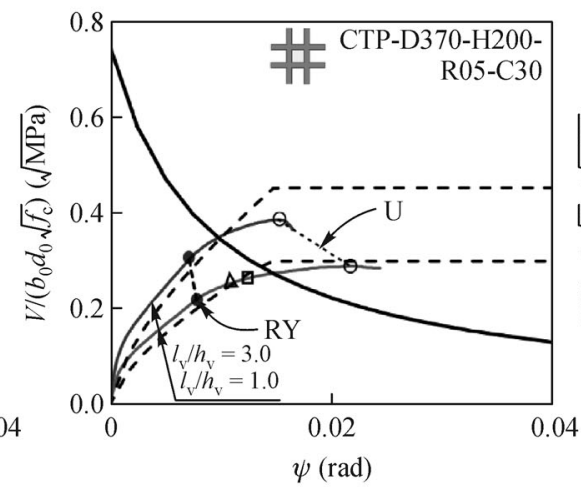

(b)

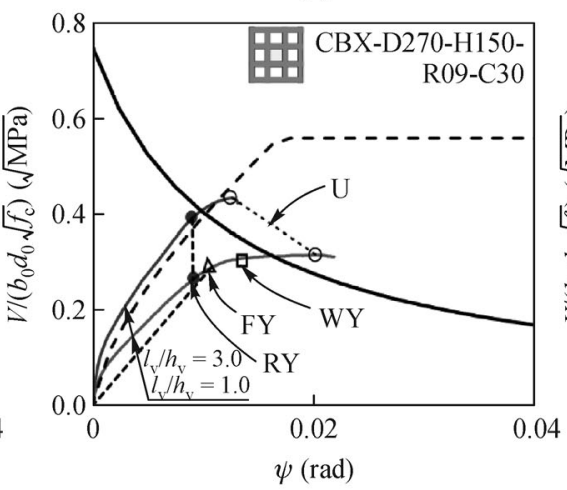

(e)

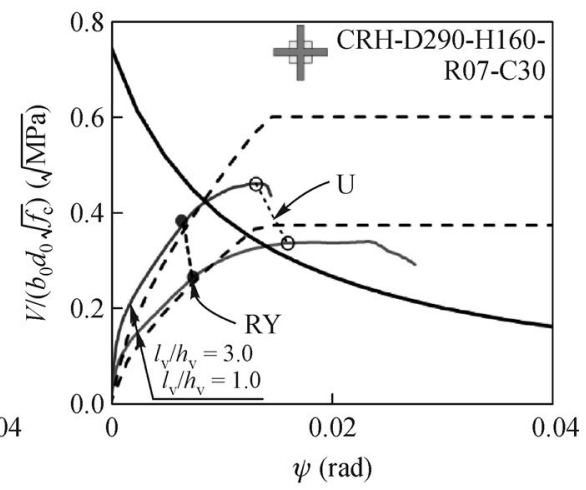

(c)

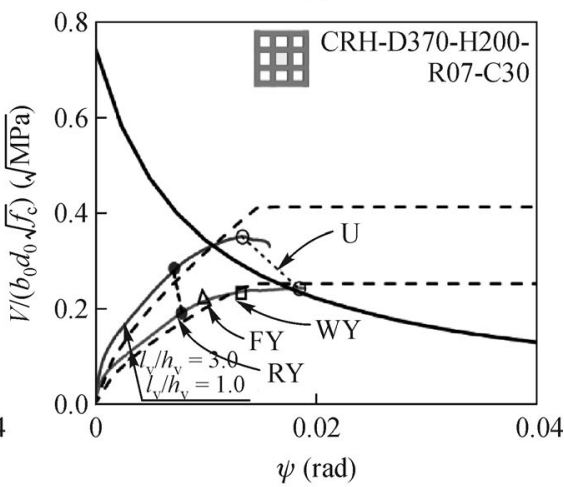

(f)

Fig. 11 Influence of the slab radius on the slab capacity and rotations: (a) CTP, $d=270 \mathrm{~mm}, h_{\mathrm{v}}=150 \mathrm{~mm}, \rho_{\mathrm{l}}=0.7 \%, f_{\mathrm{c}}=30 \mathrm{MPa}$; (b) CTP, $d=370 \mathrm{~mm}, h_{\mathrm{v}}=200 \mathrm{~mm}, \rho_{\mathrm{l}}=0.5 \%, f_{\mathrm{c}}=30 \mathrm{MPa}$; (c) CRH, $d=290 \mathrm{~mm}, h_{\mathrm{v}}=160 \mathrm{~mm}, \rho_{\mathrm{l}}=0.7 \%, f_{\mathrm{c}}=30 \mathrm{MPa}$; (d) CRH, $d=$ $370 \mathrm{~mm}, h_{\mathrm{v}}=200 \mathrm{~mm}, \rho_{1}=0.5 \%, f_{\mathrm{c}}=30 \mathrm{MPa}$; (e) CBX, $d=270 \mathrm{~mm}, h_{\mathrm{v}}=150 \mathrm{~mm}, \rho_{1}=0.9 \%, f_{\mathrm{c}}=30 \mathrm{MPa} ;(\mathrm{f}) \mathrm{CBX}, d=370 \mathrm{~mm}, h_{\mathrm{v}}=$ $200 \mathrm{~mm}, \rho_{\mathrm{l}}=0.7 \%, f_{\mathrm{c}}=30 \mathrm{MPa}$.

$\left(l_{\mathrm{v}} / r_{\mathrm{s}}=0.72\right.$ and 0.22 , and $l_{\mathrm{v}} / r_{\mathrm{s}}=0.05$ and 0.15 , respectively), leads to an increase in rotations $\psi$ at ultimate, which indicates a more flexible slab behavior. In the latter case, even if relatively high $\rho_{1}>1.1 \%$ is used, for CTP shear-heads with $l_{\mathrm{v}} / h_{\mathrm{v}}=3.0$, full yielding of the steel profiles occurred, due to the higher bending moment carried by the slab strips containing the shear-heads.

A direct comparison between the three shear-head types investigated indicate that when the same $l_{\mathrm{v}} / h_{\mathrm{v}}$ is considered, the flat slab behavior in terms of kinematics and yielding sequence is virtually identical. The geometry of CBX shear-heads involves an increased number of steel profiles in comparison to CTP and $\mathrm{CRH}$, hence implicitly increasing the local stiffness of the slab. The above observations indicate that for relatively short $l_{\mathrm{v}} / h_{\mathrm{v}}$, the behavior of a flat slab with shear-heads tends toward conventional RC behavior, while for relatively long shearheads this tends toward steel-concrete composite response. A relatively long shear-head benefits from an increased steel-concrete contact area, leading to an enhanced composite behavior in comparison to cases of relatively short shear-heads. In addition to the numerical damage maps indicating inclined failure surfaces, the ultimate envelopes $(U)$ in proximity to the punching shear failure criterion (FC) show that punching occurred at ultimate for cases with intermediate to high $\rho_{1}$ although shear-head flange yielding (FY) was also recorded.

\subsection{Shear-head cross-section and slab thickness}

The influence of the ratio between the shear-head crosssection, shear-head type (CTP, CRH, CBX) and slab thickness was examined in three parametric studies. Initially, the slab effective depth $\mathrm{d}$ was varied from 170 to $370 \mathrm{~mm}$ for two embedment length ratios $l_{\mathrm{v}} / h_{\mathrm{v}}=1.0$ and $l_{\mathrm{v}} / h_{\mathrm{v}}=3.0$. Each of the two ratios was also used in conjunction with three reinforcement ratios $\rho_{1}$ between 0.4 and $1.1 \%$. In addition, the shear-head cross-section was varied from C $100 \mathrm{~mm} \times 50 \mathrm{~mm} \times 10 \mathrm{~mm}$ to $200 \mathrm{~mm} \times$ $75 \mathrm{~mm} \times 23 \mathrm{~mm}$ for CTP and CBX and $100 \mathrm{~mm} \times$ $100 \mathrm{~mm} \times 6 \mathrm{~mm} \times 10 \mathrm{~mm}$ to $200 \mathrm{~mm} \times 200 \mathrm{~mm} \times 9 \mathrm{~mm}$ $\times 15 \mathrm{~mm}$ for $\mathrm{CRH}$ shear-heads. For compactness, 


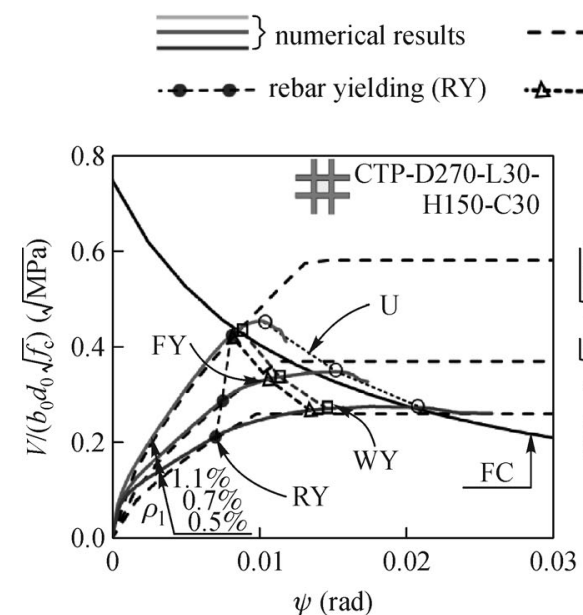

(a)

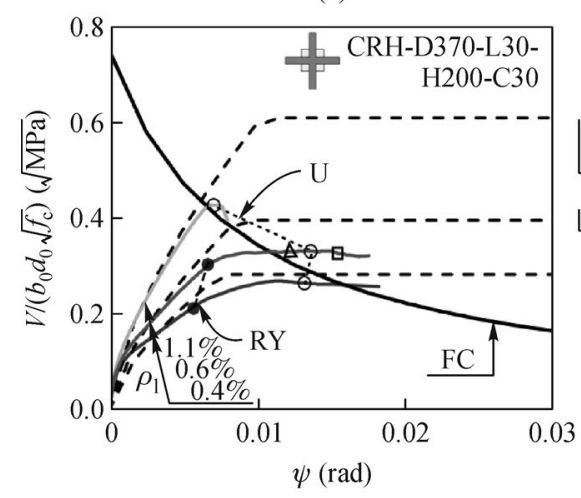

(d)

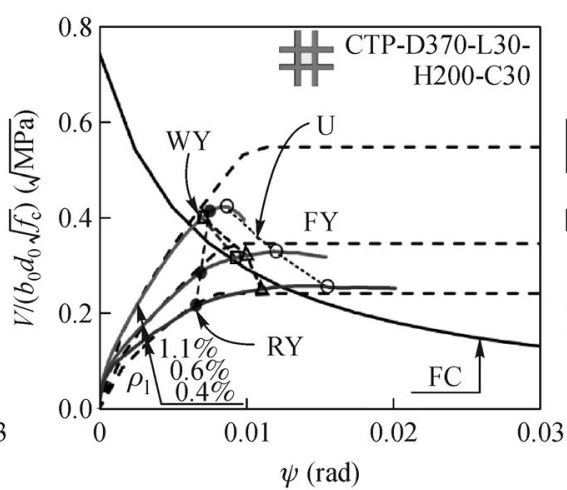

(b)

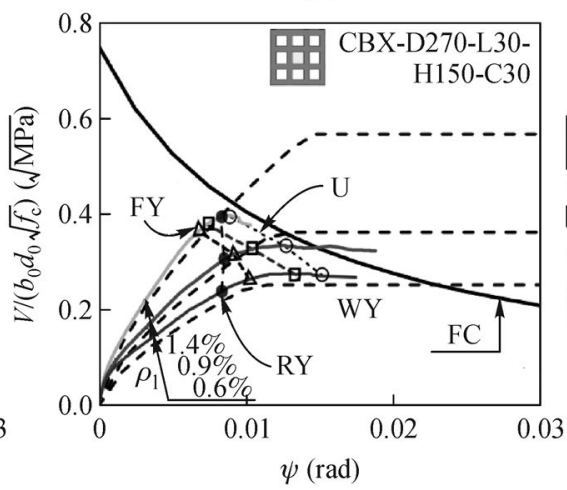

(e)

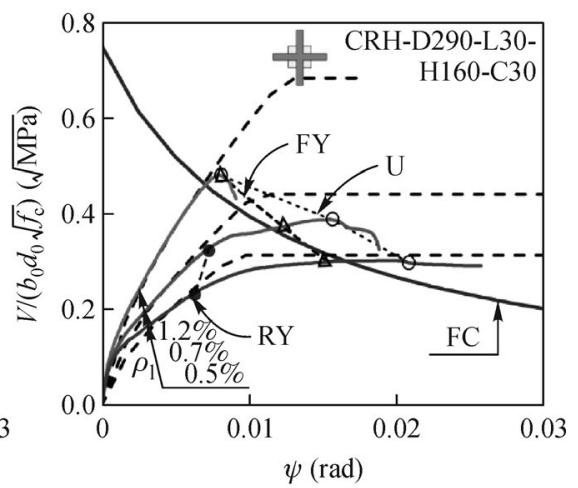

(c)

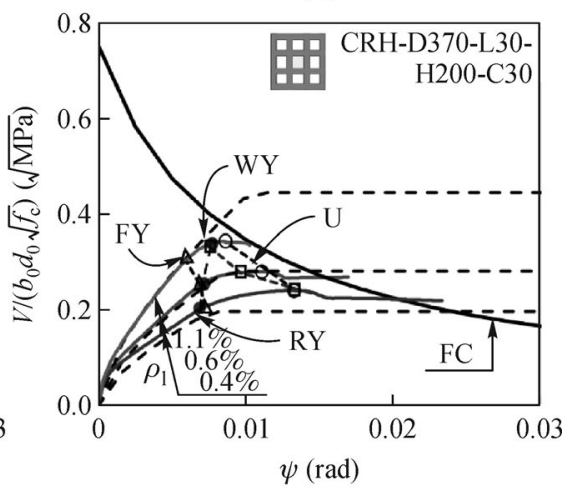

(f)

Fig. 12 Influence of the slab depth on the slab capacity and rotation: (a) CTP, $d=270 \mathrm{~mm}, l_{\mathrm{v}} / h_{\mathrm{v}}=3.0, h_{\mathrm{v}}=150 \mathrm{~mm}, f_{\mathrm{c}}=30 \mathrm{MPa}$; (b) CTP, $d=370 \mathrm{~mm}, l_{\mathrm{v}} / h_{\mathrm{v}}=3.0, h_{\mathrm{v}}=200 \mathrm{~mm}, f_{\mathrm{c}}=30 \mathrm{MPa}$; (c) CRH, $d=290 \mathrm{~mm}, l_{\mathrm{v}} / h_{\mathrm{v}}=3.0, h_{\mathrm{v}}=160 \mathrm{~mm}, f_{\mathrm{c}}=30 \mathrm{MPa}$; (d) CRH, $d=$ $370 \mathrm{~mm}, l_{\mathrm{v}} / h_{\mathrm{v}}=3.0, h_{\mathrm{v}}=200 \mathrm{~mm}, f_{\mathrm{c}}=30 \mathrm{MPa} ;(\mathrm{e}) \mathrm{CBX}, d=270 \mathrm{~mm}, l_{\mathrm{v}} / h_{\mathrm{v}}=3.0, h_{\mathrm{v}}=150 \mathrm{~mm}, f_{\mathrm{c}}=30 \mathrm{MPa} ;(\mathrm{f}) \mathrm{CBX}, d=370 \mathrm{~mm}, l_{\mathrm{v}} / h_{\mathrm{v}}$ $=3.0, h_{\mathrm{v}}=200 \mathrm{~mm}, f_{\mathrm{c}}=30 \mathrm{MPa}$.

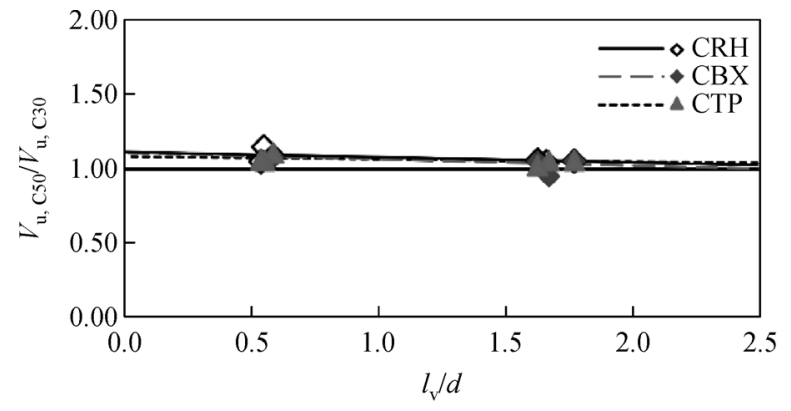

(a)

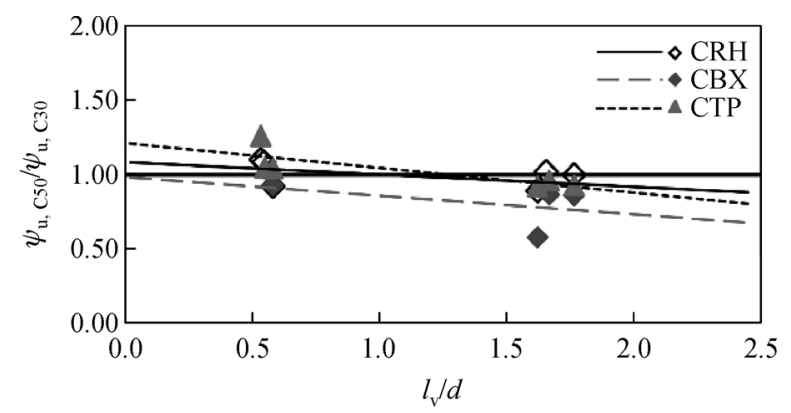

(b)

Fig. 13 Relationship between (a) capacity ratio and $l_{\mathrm{v}} / d$, (b) rotation ratio and $l_{\mathrm{v}} / d$; for concrete strength of 30 and $50 \mathrm{MPa}$.

only selected results of these variations are depicted in Figs. 12(a)-12(f) which need to be considered in conjunction with the results given in Fig. 10.

Similar to other observations made before, members with low $\rho_{1}=0.4 \%-0.5 \%$ developed inelastic strains in the longitudinal bars (RY). Members with short shear-heads $\left(l_{\mathrm{v}} / h_{\mathrm{v}}=1.0 ; l_{\mathrm{v}} / r_{\mathrm{s}}=0.08\right)$ exhibited elastic shear-head behavior with failure triggered by crushing at the shearhead tip. For longer CTP and CRH shear-heads $\left(l_{\mathrm{v}} / h_{\mathrm{v}}=\right.$ $\left.3.0 ; l_{\mathrm{v}} / r_{\mathrm{s}}=0.22\right)$ and relatively thin slabs $(d=170 \mathrm{~mm})$, the behavior was governed by punching at ultimate with inelastic strains occurring in the flexural reinforcement (RY) or shear-head flanges (FY), depending on the slab configuration (Figs. 10(b) and 10(e)). 


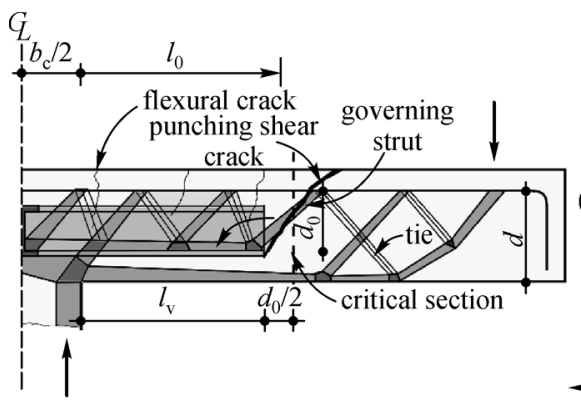

(a)

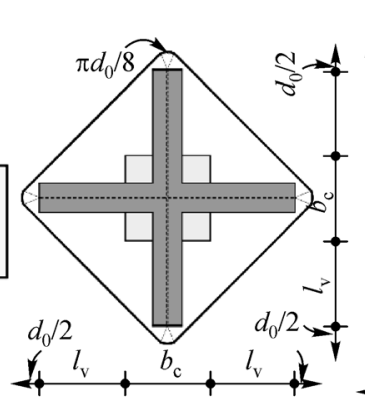

(b)

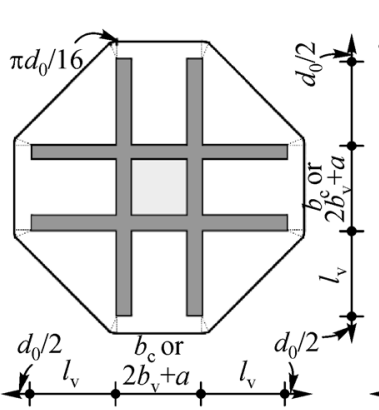

(c)

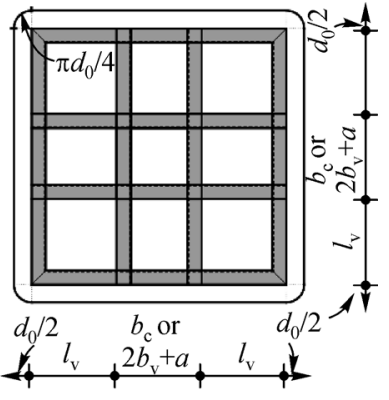

(d)

Fig. 14 (a) Strut transfer scheme for slabs with shear-heads; control perimeter for: (b) slabs with cruciform H/I shear-heads (CRH), (c) cruciform with two parallel channels (CTP), (d) closed box shear-heads (CBX).

As the slab thickness increases $(d=270-370 \mathrm{~mm})$ some differences occur in the response of CBX shear-heads in comparison to cases with $d=170 \mathrm{~mm}$ (Figs. 12(e), 12(f), and $10(\mathrm{~h})$ ). For these cases, the ultimate envelopes (U) show trends below (FC), which identify failure mechanisms different than those described above. For these cases with $\rho_{1}$ up to $1.4 \%$, the failure was triggered by a more rapid propagation of yield in the steel profiles than in the steel rebars, leading to a flexurally-governed behavior by the shear-head. Similarly, CTP members with $(d=270$ $370 \mathrm{~mm}$ ), having shear-heads made of parallel flange channels as CBX, indicated a response governed by complete yielding of the steel profiles in which the yielding propagated rapidly from the flange to the web. However, for these specimens, the failure envelope (U) was in the vicinity or above the failure criterion (FC) indicating a flexurally-governed punching shear failure triggered by the shear-head flange and web yielding (Figs. 10(b) and 12). It was previously shown that for relatively short shear-heads with relatively thin webs, in hybrid flat slabs connected to steel columns, failure may be triggered by web yielding (WY). Such web yielding was produced by a sudden slip of the shear-head from the embedding concrete which led to a premature punching shear failure [70]. Although, for the cases illustrated in Fig. 12, web yielding occurred, this was a consequence of progressive yielding of the steel profile from the top flange through the web and into the bottom flange.

\subsection{Concrete strength}

The influence of the concrete properties on the response of flat slabs with shear-heads was examined by modifying the compressive strength from $f_{\mathrm{c}}=30$ to $50 \mathrm{MPa}$ for all CTP, $\mathrm{CRH}$, and CBX models with $l_{\mathrm{v}} / h_{\mathrm{v}}=1.0-3.0 ; \rho_{1}=0.6 \%$ $0.9 \%, d=170-370 \mathrm{~mm}$, while the slab geometry was kept constant. For compactness, only brief discussions are presented here, but the $V_{\mathrm{u}}$ and $\Psi_{\mathrm{u}}$ obtained for all the cases considered are used for the subsequent analytical assessments.

Close inspection on the results indicated that for CTP shear-heads, an increase of $f_{\mathrm{c}}$ from 30 to $50 \mathrm{MPa}$ led to an increase in $V_{\mathrm{u}}$ in the range of $2 \%-11 \%$ (Fig. 13(a)). The slab rotation $\Psi_{\mathrm{u}}$ was between $4 \%$ and $26 \%$ larger for shearheads with $l_{\mathrm{v}} / h_{\mathrm{v}}=1.0$, while this decreased by up to $8 \%$ for slabs with $l_{\mathrm{v}} / h_{\mathrm{v}}=3.0$ (Fig. 13(b)). On the other hand, for the models with CRH shear-heads and $f_{\mathrm{c}}=50 \mathrm{MPa}, V_{\mathrm{u}}$ was $5 \%-15 \%$ higher than the case with lower $f_{\mathrm{c}}$, while $\Psi_{\mathrm{u}}$ was mostly the same with an $\Psi_{\mathrm{u}, \mathrm{C} 50} / \Psi_{\mathrm{u}, \mathrm{C} 30}=1.00$. For CBX cases, an increase of $3.3 \%$ in $V_{\mathrm{u}}$ combined with a reduction in $\Psi_{\mathrm{u}}$ of up to $20 \%$ was obtained, particularly for cases with $l_{\mathrm{v}} / h_{\mathrm{v}}=3.0$ for which the complete shear-head crosssection yielded.

The results of the parametric studies identified three modes of failure as a function of the interaction between the shear-head and surrounding concrete: steel reinforcement flexural failure due to yielding of the rebars (A); flexural failure governed by the complete shear-head yielding (B), and punching shear due to crushing with or without yielding of the reinforcement or top flange of the shear-head referred to here as a controlled failure (C). These observations, with the complementary key findings from the numerical investigations described in Sections 2 and 3, enable the validation of analytical models for a wide range of RC slab systems with shear-heads as described below.

\section{Analytical models and design considera- tions}

\subsection{Punching shear strength}

An axisymmetric rotational model, which considers that relatively stiff shear-heads in conjunction with reinforcement transfer the load from steel columns to the RC flat slab through cruciform shear-heads, was proposed previously for hybrid systems by authors [12]. The model can be directly employed for assessing the complete $V-\psi$ response for the configurations investigated in this paper. Since the slab flexibility is the governing factor for the assessment of flat slab punching shear strength [53], the $V$ - 
$\psi$ prediction must have a significant degree of reliability. Hence, a focal point in the parametric investigations described in Section 3 was the prediction of $V-\psi$ for a wide range of configurations. Based on the numerical results, a bilinear model, derived from the axisymmetric model described above, and compliant with current design procedures [79], is proposed herein.

A factor $\lambda_{\psi}$ in Eq. (4) that accounts for slab flexibility through the reinforcement ratio $\rho_{1}$ and shear-head embedment length $l_{\mathrm{v}}$ was derived from regression to numerical results and is validated against the results from the parametric assessments presented in Section 3. It is worth noting that for connections between steel columns and hybrid RC flat slabs by means of shear-heads, the contribution of $r_{\mathrm{s}} / l_{\mathrm{v}}$ to the slab flexibility parameter $\lambda_{\psi}$ is significantly higher in the case of RC columns to RC flat slabs in the form investigated in this paper, as the force is carried through shear-heads and flexural reinforcement only, without the contribution of the column support. The rotation $\psi$ of the RC member with shear-heads, estimated using Eq. (4), depends on the section utilization factor $V_{\mathrm{i}} / V_{\text {flex }}$, in which $V_{\text {flex }}$ is the flexural strength (Eq. (5)) of the slab and $V_{\mathrm{i}}$ is the shear action. Other parameters include the slab radius $r_{\mathrm{s}}$, yield strength $f_{\mathrm{ys}}$ and elastic modulus $E_{\mathrm{s}}$

of the longitudinal reinforcement, the slab effective depth $d$, and the slab flexibility factor $\lambda_{\psi}$, The flexural strength $V_{\text {flex }}$ is a function of $\eta$ which accounts for the in-plane distribution of the shear-heads within the slab, the plastic moments of the composite sectors $m_{\mathrm{Rk}}$ that include the shear-heads (Eqs. (6a)-(6b) and the concrete sectors $m_{\mathrm{Rc}}$ (Eq. (6c)), as well as the slab configuration $\left(l_{\mathrm{v}}, r_{\mathrm{s}}, r_{\mathrm{e}}, r_{\mathrm{c}}\right)$. The plastic moments per unit width in Eq. (6) may be determined from assumptions of linear strain compatibility in the cross-section, in which yielding occurs first in the tension reinforcement.

$$
\psi=\lambda_{\psi} \frac{r_{\mathrm{s}}}{d} \frac{f_{\mathrm{ys}}}{E_{\mathrm{s}}}\left(\frac{V_{i}}{V_{\text {flex }}}\right)^{3 / 2}, \text { where } \lambda_{\psi}=\frac{2}{3}\left(100 \rho_{l}\right)^{\frac{1}{3}}\left(\frac{r_{\mathrm{s}}}{l_{\mathrm{v}}}\right)^{\frac{1}{20}},
$$

$$
\begin{gathered}
V_{\text {flex }}=\pi\left(\eta \frac{l_{\mathrm{v}}}{r_{\mathrm{s}}} m_{\mathrm{Rk}}+\left(2-\eta \frac{l_{v}}{r_{\mathrm{s}}}\right) m_{\mathrm{Rc}}\right) \frac{r_{\mathrm{e}}}{r_{\mathrm{s}}-r_{\mathrm{c}}}, \\
\text { where } \eta=8 \sin ^{-1}\left(0.5 b_{\mathrm{v}} / r_{\mathrm{c}}\right),
\end{gathered}
$$

$$
\begin{gathered}
m_{\mathrm{Rc}}=f_{\mathrm{ys}} A_{\mathrm{s}}\left(d-\frac{c_{\mathrm{c}}}{2}\right), \text { where } c_{\mathrm{c}}=\frac{f_{\mathrm{ys}} A_{\mathrm{s}}}{\lambda f_{\mathrm{c}} b_{\mathrm{c}}} \\
\text { and }\langle x\rangle:(<0=0 ; \geqslant 0=x) .
\end{gathered}
$$

Figures 10-12 illustrate the $V-\psi$ predictions using Eqs. (4)-(6) for the selected numerical models plotted against the results from the simulations. Considering the limitations of a bilinear approach, the predicted results are in good agreement with the stiffness of RC flat slabs obtained from simulations, particularly for the CTP and CRH cases. In the case of CBX flat slabs, the results show slight flexibility compared to that obtained from numerical simulations, mostly due to the more robust form of CBX shear-heads. However, a lower predicted stiffness in conjunction with the failure criterion (Eq. (3) [90]) results in a conservative prediction of the punching shear strength $V_{\text {u }}$. The predicted $V_{\text {flex }}$, attained in members with relatively low reinforcement ratios $\rho_{1}=0.3 \%-0.6 \%$, is in good agreement with all numerical results. The analytical results show consistency with the numerical results since the full flexural capacity is reached only for models with very low levels of $\rho_{\mathrm{l}}$

In terms of code provisions, the North American guidelines ACI318-14 [80] are largely based on the design procedure proposed by Corley and Hawkins [6], following the test results on members with cruciform shear-heads (Figs. 8 and 9). In this model, $V_{\mathrm{u}}$, estimated with Eq. (7), is a function of $f_{\mathrm{c}}, d$, a limiting factor (0.33) and a control perimeter $b_{0}$, which considers that the critical slab sections for punching shear intersect each shear-head at threequarters the distance $0.75 l_{\mathrm{v}}$ from the column face, but not closer than $d / 2$ from the column face (in this investigation, $l_{\mathrm{v}}$ is the distance from the column face).

$$
V_{\mathrm{c}}=0.33 \sqrt{f_{\mathrm{c}}} b_{0} d .
$$

No specific provisions are given in Eurocode 2 (EC2) [78] to assess the punching shear strength of members with shear-heads. The value of $V_{\mathrm{u}}$ for conventional RC flat slabs without shear reinforcement and without pre-stressing is dependent on the size effect $[1+(200 / d) 1 / 2<2.0], \rho_{\mathrm{l}}, f_{\mathrm{c}}, d$ and $b_{0}$ situated at $2 d$ from the column face. As observed in Fig. 9 and in previous tests $[12,76]$, a relatively stiff shearhead shifts the critical zone outside the shear-head region. 
Hence, the strength assessment of flat slabs with shearheads can be comparable to the verification for failure outside of the shear-reinforced region for members provided with transverse bars. The control perimeter accounts for a rounded control section situated at $k \times d$ from the shear-head tip $(k=1.5)$ extended in both sides of the shear-head by a distance of $1.0 d$.

$$
V_{\mathrm{c}}=0.18(1+\sqrt{200 / d})\left(100 \rho_{l} f_{\mathrm{c}}\right)^{1 / 3} b_{0} d .
$$

On the other hand, the Model Code 2010 [45] offers recommendations for the design of flat slabs with CBX shear-heads by considering it as a rigid support region. It also accounts for the shear-head penetration to the shear effective depth $d_{0}$ considered in the $V_{\mathrm{u}}$ assessments (Eq. (9)). The parameters involved in strength assessments are the $k_{\psi}$ factor (Eq. (10a)), representing a conservative function of the failure criterion in Eq. (3) [90]. This is dependent on $\psi, d$, and a $k_{\mathrm{dg}}$ parameter as a function of the maximum aggregate size $d_{\mathrm{g}}$. For Level II Approximation (LoA II), the rotation of a RC slab at a specific shear force is given by Eq. (10b) (where $m_{\mathrm{S}}$ is the design bending moment, $m_{\mathrm{R}}$ is the plastic moment of a RC cross-section and $r_{\mathrm{s}}=0.22 \mathrm{~L}$ is a function of the member moment span $L$ ). The critical section is at $d_{0} / 2$ from the strut support and considers rounded corners.

$$
\begin{gathered}
V_{\mathrm{c}}=k_{\psi} \sqrt{f_{\mathrm{c}}} b_{0} d_{0}, \\
k_{\psi}=1 /\left(1.5+0.9 \cdot \psi \cdot d \cdot k_{\mathrm{dg}}\right) \leqslant 0.6,
\end{gathered}
$$

where

$$
\begin{gathered}
k_{\mathrm{dg}}=32 /\left(16+d_{\mathrm{g}}\right)>0.75, \\
\psi=1.5 \frac{r_{\mathrm{s}}}{d} \frac{f_{\mathrm{ys}}}{E_{\mathrm{s}}}\left(\frac{m_{\mathrm{s}}}{m_{\mathrm{R}}}\right)^{1.5} .
\end{gathered}
$$

Figure 15 summarizes the ratio between the test or numerical strength and predicted strength $\left(V_{\text {num/test }} / V_{\text {calc }}\right)$ versus the ratio between the test or numerical result and the flexural strength, from the application of the existing codified guidelines (Eqs. (7)-(10)) and Eqs. (1)-(6) proposed in this paper. Values of $V_{\text {num/test }} / V_{\text {calc }}$ above unity depict conservative predictions, whereas those below unity represent unconservative estimates. As indicated in Fig. 15(a), the ACI318 strength assessments give an average of 1.12 (with a COV of $21 \%$ ) between the punching shear strength obtained from numerical models or tests and $V_{\mathrm{u}}$ predicted. The influence of the slab flexibility is captured reasonably well, with a slight tendency of under-estimation of the capacity for flexible slabs with relatively low reinforcement ratio and $V_{\text {num/test }} /$ $V_{\text {flex }} \approx 1.0$. The modified assumptions regarding the definition of $b_{0}$, as described previously for EC2, show conservative predictions with an average of 1.52 and a
COV of 0.25 , with a tendency for offering conservative estimates for most configurations (Fig. 15(b)). It is worth noting that for the assessments using the MC2010 guidelines, $\psi$ and $m_{\mathrm{R}}$ were assessed without considering the influence of the shear-head to slab rotation and plastic moment, as prescribed by the code. Consequently, as depicted in Fig. 15(c), LoA II of MC 2010 shows large scatter primarily because a key parameter is a more flexible $\psi$, hence leading implicitly to overly-conservative estimates with an average of 1.30 and a COV of 0.28 .

In contrast, the assessment models proposed in this paper, in which the punching shear strength is the result of the intersection between the $V-\psi$ response, from a bi-linear representation (Eq. (4)) and the failure criterion (Eq. (3)) [94] and accounts for a shear-head dependent control perimeter, offer generally improved and consistent strength estimates. The ratios between the predicted strengths and the test or numerical strengths indicate an average of 1.06 and a COV of 0.13 (Fig. 15(d)). This indicates that the suggested assessment approach can predict accurately the ultimate strength, for both low and high reinforcement ratios represented by the wide range of $V_{\text {num/test }} / V_{\text {flex }}$. Additionally, an appraisal of the MC2010 design approach by considering the influence of the shear-head on $\psi$ and $m_{\mathrm{R}}$ (Eqs. (4) and (11)), while the slab radius is a function of the position of the supports, shows improved predictions in comparison to the unmodified conventional approach with an average of 1.23 and COV of 0.21 (Fig. 15(e)).

$$
m_{\mathrm{R}, \mathrm{avg}}=(1-\eta / 2) m_{\mathrm{R}, \mathrm{c}}+\eta\left(m_{\mathrm{R}, \mathrm{c}}+m_{\mathrm{R}, \mathrm{k}}\right) / 4 .
$$

For these assessments, the section utilization factor $m_{\mathrm{S}} / m_{\mathrm{R}}$ can be estimated using an average plastic moment (Eq. (11)) for the case when no eccentricity is acting on the member, by replacing the $\left(V_{i} / V_{\text {flex }}\right)$ in Eq. (4). The results above indicate that the proposed model offers a simple and practical method for design purposes, while considering a more realistic approach compared to existing code procedures.

\subsection{Shear-head properties}

The embedment length $l_{\mathrm{v}}$ of a shear-head may be determined using Eqs. (12) based on the assumption that the critical section is situated at $d_{0} / 2$ from the shear-head tip. This results from the length of the control perimeter $b_{0 \text {,req }}$ as a function of the shear action $V_{i}$ in which $k_{\psi}$ is assessed using Eq. (3). Equation (10a) may also be used for assessing $k_{\psi}$, yet this results in a longer embedment length, due to the more conservative nature of the expression. Figure 16(a) illustrates the relationship between the ratio of $b_{0 \text {,req }}$, resulting from Eq. (12a), and $b_{0}$ using the layout indicated in Fig. 14(b)-14(d), against the $l_{\mathrm{v}} / r_{\mathrm{s}}$ ratio, for all numerical models and tests failing in punching shear. As the average $b_{0, \text { req }} / b_{0}$ is 1.06 , this indicates that the assumption regarding the shape of $b_{0}$, along with the 


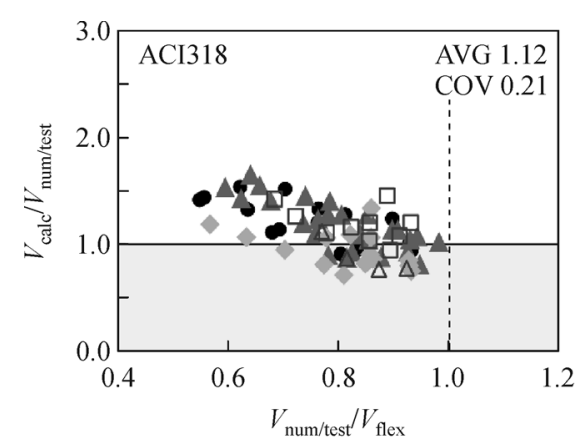

(a)

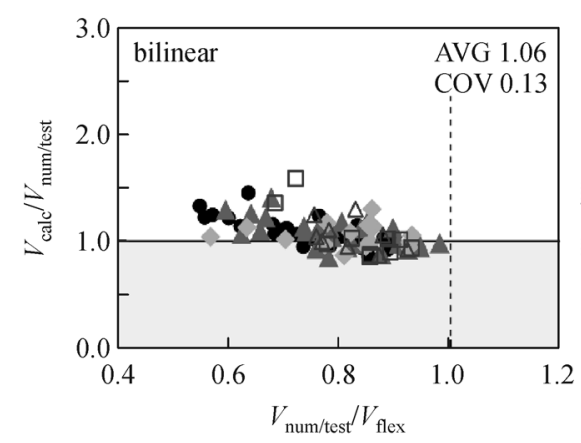

(d)

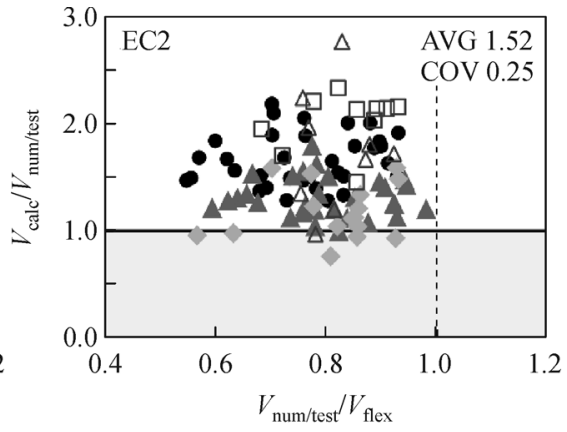

(b)

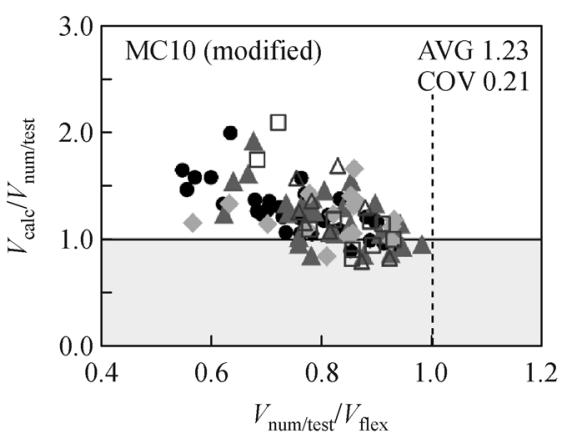

(e)

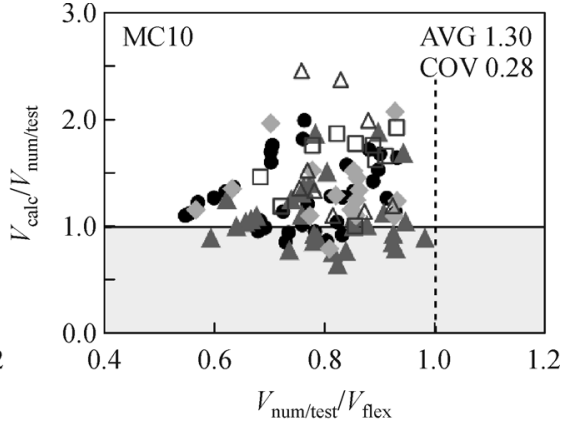

(c)

numerical:

- $\mathrm{CRH}$

- CTP

- CBX tests:

$\triangle$ Chana and Birjandi [20]

$\square$ Corley and Hawkins [6]

Fig. 15 Strength predictions for existing models: (a) ACI318, (b) Eurocode 2, (c) Model Code 2010; proposed models: (d) bilinear, (e) modified Model Code 2010.

suggested approach for assessing $b_{0, \text { req }}$, is reliable and may be used to determine the required embedment length $l_{\mathrm{v}, \mathrm{req}}$.

$$
\begin{gathered}
b_{0, \text { req }} \geqslant V_{i} /\left(k_{\psi} \sqrt{f_{\mathrm{c}}} d_{0}\right), \\
l_{\mathrm{v}, \mathrm{CTP}, \text { req }}=\left[b_{0, \mathrm{CTP}, \text { req }}-4\left(d_{0} \sin \frac{\pi}{8}+\left(2 b_{v}+a\right)+\frac{\pi d_{0}}{8}\right)\right] \\
/ 4 \sqrt{2} \text { for } \mathrm{CTP} \\
l_{\mathrm{v}, \mathrm{CRH}, \text { req }}=\left[b_{0, \mathrm{CRH}, \text { req }}-4\left(\frac{b_{\mathrm{c}} \sqrt{2}}{2}+d_{0} \sin \frac{\pi}{8}+\frac{\pi d_{0}}{8}\right)\right] \\
/ 4 \sqrt{2} \text { for } \mathrm{CRH}, \\
l_{\mathrm{v}, \mathrm{CBX}, \text { req }}=\left[b_{0, \mathrm{CBX}}-4\left(2 b_{v}+a+\frac{\pi d_{0}}{4}\right)\right] / 8 \text { for CBX. }
\end{gathered}
$$

The results of the numerical simulations also showed that short shear-heads, in the range of $l_{\mathrm{v}} / h_{\mathrm{v}} \leqslant 1.0$, are unlikely to be able to support the force-transferring struts, which may lead to compression yielding of the bottom flange and potential slip. As observed in Fig. 10, as the shear-head length increases composite action may develop and yielding of the shear-head may occur (e.g., $\left.l_{\mathrm{v}} / h_{\mathrm{v}}>3.0\right)$. Depending on $\rho_{\mathrm{l}}$, one of the steel tension members may yield with punching shear eventually governing. For relatively long shear-heads $\left(l_{\mathrm{v}} / h_{\mathrm{v}}=5.0\right)$, the yielding of the flange shear-head (FY) is close to the ultimate envelopes (U), yet relatively distant from the failure criterion, indicating a failure governed by the shearhead behavior.

Based on these observations, the shear-head section size should be determined from Eq. (13a), considering that only half of the force may be transferred by the shear-head while the remaining half is transferred directly to the columns (e.g., Fig. 10(a)). A conservative of $h_{\mathrm{v}} / d \geqslant 0.5$ limit should also be applied to avoid possible shear-head web triggered failures $[12,69,70]$. Since the force is transferred from the slab to the column through struts supported on the bottom flange, to ensure a smooth transfer, the bottom flange should be relatively stiff in order to avoid failure in compression in the steel insert. The minimum shear-head width $b_{\mathrm{v}}$ may be determined using Eq. (13b), based on the assumption that the transferring struts are supported 
through the entire $l_{\mathrm{v}}$, in which $\sigma_{\mathrm{c}, \max }$ is the strut crushing strength [79].

Figure 16(b) on the other hand shows the relationship between the moment demand to capacity $M_{\mathrm{v}, i} / M_{\mathrm{v}, i, \mathrm{Rd}}$ for each shear-head for numerical models in which the flange yielding (FY) was recorded, against the $l_{\mathrm{v}} / r_{\mathrm{s}}$ ratio. The moment demand $M_{\mathrm{v}, i}$ was assessed considering the force distribution illustrated in Fig. 17 resulting from integration of bending stresses for CRH shear-heads along the cracked cross-section. This indicated that the shear-head flexibility influences the position of the reaction force with longer shear-heads pushing the force toward the column. In contrast, shorter shear-heads translate the reaction force toward the shear-head tip. To accommodate the influence of the shear-head flexibility on the moment demand in the shear-head, a $\lambda_{\mathrm{m}}$ parameter is introduced (Eq. (13c). In design, the moment capacity of a shear-head, estimated using Eq. (13d) has to be higher than the demand (Eq. (13c)). As indicated in Fig. 16(b), for the majority of cases in which (FY) was observed, $M_{\mathrm{v}, i} / M_{\mathrm{v}, i, \mathrm{Rd}}$ is above 1.0 , indicating that the above assumptions may be employed for practical assessment.

$$
\begin{gathered}
A_{\mathrm{vv}} \geqslant \frac{1}{2} \frac{V_{i}}{n_{\mathrm{v}}} \frac{\sqrt{3}}{f_{\mathrm{y}}} \\
b_{\mathrm{v}} \geqslant \frac{V_{i}}{n_{\mathrm{v}}} \frac{1}{\sigma_{\mathrm{c}, \max } l_{\mathrm{v}}}, \text { where } \sigma_{\mathrm{c}, \max }=0.55\left(30 / f_{\mathrm{c}}\right)^{1 / 3} f_{\mathrm{c}} \\
M_{\mathrm{v}, i}=\lambda_{\mathrm{m}} l_{\mathrm{v}} \frac{V_{i}}{n_{\mathrm{v}}}, \text { where } \lambda_{\mathrm{m}}=0.75\left(1-l_{\mathrm{v}} / r_{\mathrm{s}}\right), \\
M_{\mathrm{v}, i} \leqslant W_{\mathrm{v}, \mathrm{p}} f_{\mathrm{yv}} .
\end{gathered}
$$

The results from the numerical assessments presented in Sections 2 and 3 enabled the definition of the above

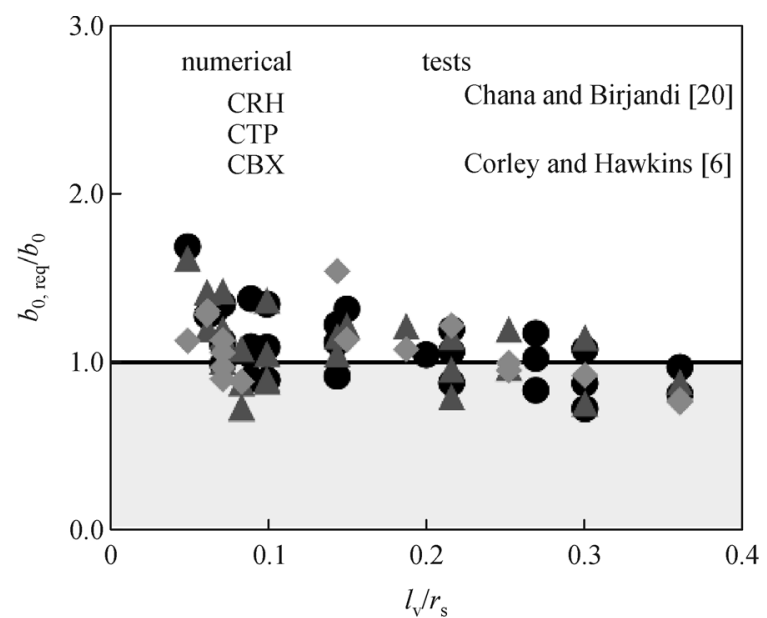

(a) expressions for the design of shear-heads in RC flat slabs. As a general guide, after the assessment of the shear-head section size using Eqs. (13), $h_{\mathrm{v}}$ should be at least $d / 2$, while the maximum shear-head depth would be limited by practical aspects including slab thickness, amount of longitudinal reinforcement and concrete cover. For a reliable strut support, it is recommended that the bottom flange of the shear-head is located within the compression zone of the slab. Members provided with low to intermediate reinforcement (e.g., $\rho_{1}=0.75 \%$ ) generally reach their flexural strength when small shear-head section sizes are employed (some cases were identified in Figs. 10-12). Typically, irrespective of $l_{\mathrm{v}}$, high $\rho_{1}(>1.4 \%)$ produce elastic reinforcement behavior. The numerical results showed that for short shear-heads $\left(l_{\mathrm{v}} / r_{\mathrm{s}}<0.1\right)$, a reliable force transfer may not be realized due to yielding initiation at the bottom flange. In contrast, cases with $0.1<l_{\mathrm{v}} / r_{\mathrm{s}}<0.36$ showed effective behavior and seem generally practical. These observations point to an effective use in design of shear-heads with embedment length-to-slab radius ratios within the range of $l_{\mathrm{v}} / r_{\mathrm{s}}=0.2-$ 0.4 or above, mainly due to their practicality and stable structural behavior.

In terms of shear-head type, CTP and CRH can provide equally reliable performance in terms of bending and punching shear, as long as the distance between the two parallel profiles in CTP is lower than the column side, to avoid possible penetration of the column through the shear-head. CTP shear-heads may also interfere with the longitudinal column reinforcement and may require a more intricate layout. On the other hand, CBX shear-heads benefit from a more robust configuration, particularly for relatively stiff steel inserts, offering a continuous strut support along the shear-head edges. In terms of bending performance, CBX resemble CTP as the maximum bending action is taken by the central profiles of the CBX. Generally, shear-heads act as an equal-sized rigid

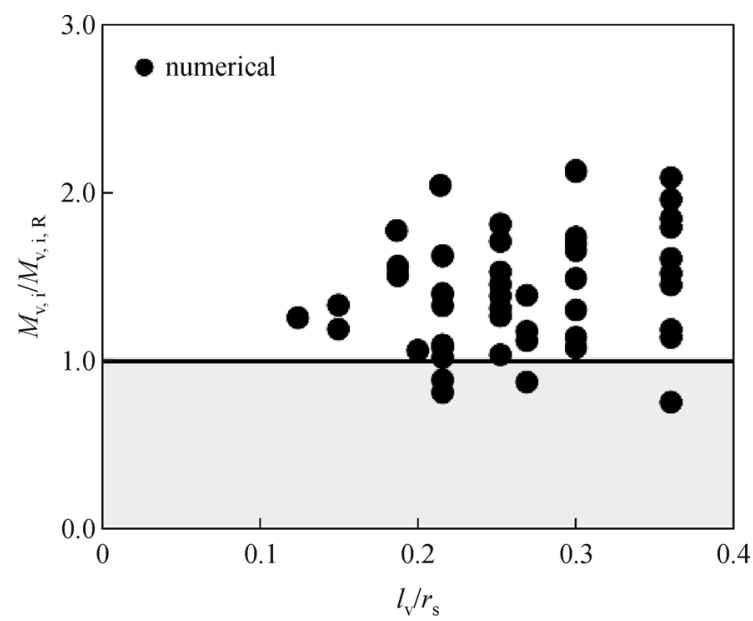

(b)

Fig. 16 Comparative assessment: (a) required control perimeter and shear-head length; (b) moment response. 


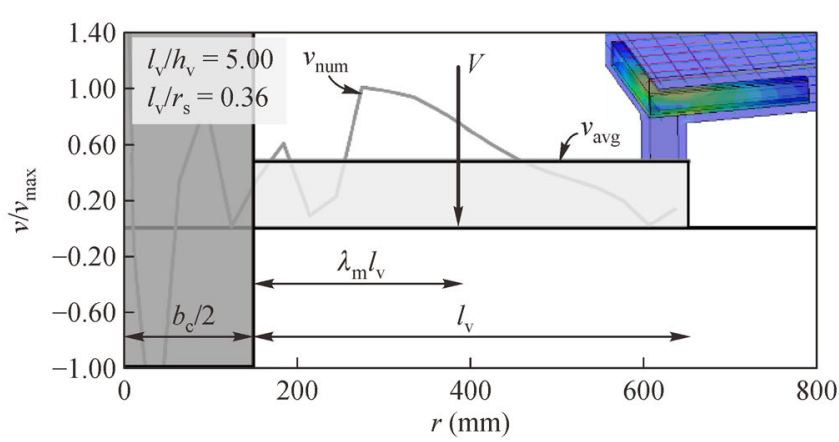

(a)

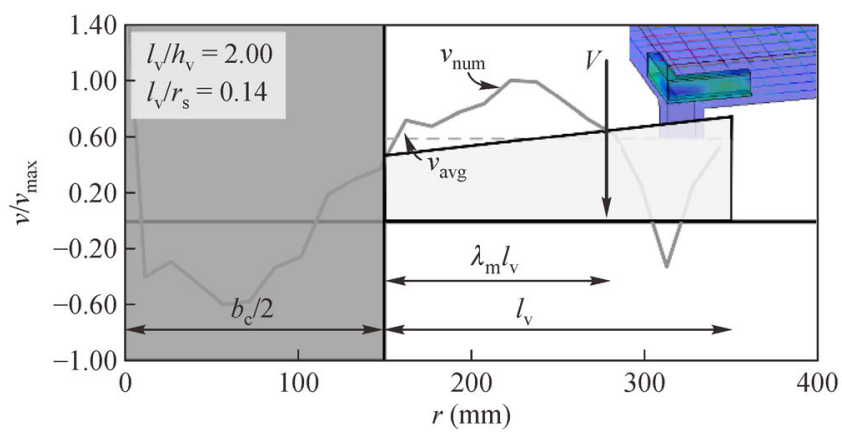

(c)

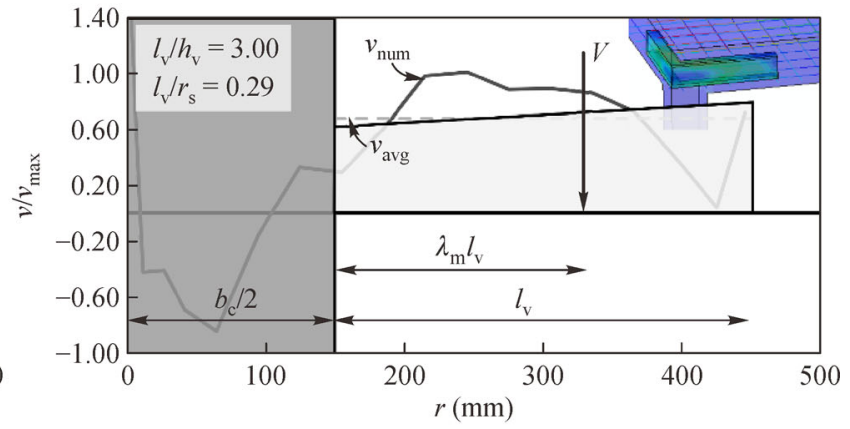

(b)

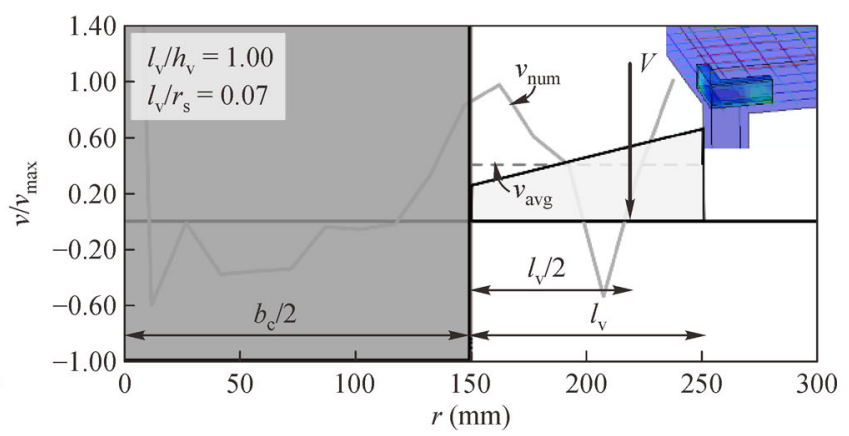

(d)

Fig. 17 Assumed force distribution for shear-heads as a function of embedment length: (a) $l_{\mathrm{v}} / h_{\mathrm{v}}=5.0, l_{\mathrm{v}} / r_{\mathrm{s}}=0.36$; (b) $l_{\mathrm{v}} / h_{\mathrm{v}}=3.00, l_{\mathrm{v}} / r_{\mathrm{s}}=$ $0.29 ;$ (c) $l_{\mathrm{v}} / h_{\mathrm{v}}=2.00, l_{\mathrm{v}} / r_{\mathrm{s}}=0.14 ;$ (d) $l_{\mathrm{v}} / h_{\mathrm{v}}=1.00 ; l_{\mathrm{v}} / r_{\mathrm{s}}=0.07$.

support, with a concentration of deformation around its circumference, translating the weak section in terms of bending and punching shear outside of the shear-head edges. The slab rotation combined with a relatively flexible shear-head, may progressively translate the failure surface within the length of the shear-head.

\section{Concluding remarks}

This paper investigated the ultimate behavior of cruciform and closed-box shear-head systems fully embedded in RC flat slabs at interior RC columns by means of nonlinear finite numerical simulations employing concrete damage plasticity models. After carrying out sensitivity studies on relevant constitutive and geometrical parameters, simulations were carried out and validated against three available test series consisting of 36 flat slab specimens with and without shear-heads. The numerical results showed good agreement with both sets of test results, indicating the reliability of the employed modeling procedures. Subsequently, a total of 122 parametric assessments were carried out by directly varying the shear-head type, shape, embedment length and section size as well as the flat slab thickness, concrete strength, reinforcement ratio, and support size. The results of the parametric investigation enabled a direct assessment of the ultimate behavior in terms of strength and deformation characteristics, as well as a qualitative assessment of the shape of the failure surface.

Based on the findings of the parametric studies, three modes of failure were identified, depending on the interaction between the shear-head and surrounding concrete: flexural failure due to yielding of the rebars, flexural failure governed by complete shear-head yielding, and punching shear due to crushing with or without yielding of the rebars or top flange of the shear-head. It was observed that comparatively stiff shear-heads act as a relatively rigid support, with a concentration of deformation around their tips, translating the weak section in terms of bending and punching shear outside of the shear-head edges. More flexible shear-heads allow increased slab rotations that influence the inclination of the governing strut, eventually leading to failure surfaces developing at lower angles, with their root moving inside the shear-head. Closed-box shear-heads tend to be more robust as these offer continuous strut support along the shear-head bottom flanges, with the shear-head encased concrete being in a multi-axial state of stress. Cruciform shear-heads are lighter and equally reliable, offering a force transfer through their length in conjunction with the column support. In terms of bending, all types contribute to the flexural capacity and bending stiffness within the shearhead region.

The rotational responses and ultimate strengths obtained from the numerical assessments were used for the 
modification and improvement of a bilinear rotational model for conventional slabs which, in conjunction with an established failure criterion, may be adopted for reliable assessment of punching shear strength. Importantly, the observations from the numerical studies permitted the definition of the shear-head dependent parameters required for design, with focus on the shear-head embedment length and section size, as well as to assess the bending moment at which yielding occurs in the shear-head. Considering the wide range of relevant parameters accounted for in the parametric assessments, the expressions proposed in this paper offer a more reliable design method in comparison with existing approaches, for all shear-head types. The proposed models are also suitable for direct practical application and implementation in codified procedures.

Open Access This article is licensed under a Creative Commons Attribution 4.0 International License, which permits use, sharing, adaptation, distribution and reproduction in any medium or format, as long as you give appropriate credit to the original author(s) and the source, provide a link to the Creative Commons licence, and indicate if changes were made.

The images or other third party material in this article are included in the article's Creative Commons licence, unless indicated otherwise in a credit line to the material. If material is not included in the article's Creative Commons licence and your intended use is not permitted by statutory regulation or exceeds the permitted use, you will need to obtain permission directly from the copyright holder.

To view a copy of this licence, visit http://creativecommons.org/licenses/ by/4.0\%.

\section{Nomenclature}

\author{
$A_{\mathrm{vv}}$ : shear-head shear active area \\ $a$ : distance between parallel steel profiles \\ $b_{0}:$ control perimeter \\ $b_{\mathrm{c}}$ : column size \\ $b_{\mathrm{v}}$ : shear-head width \\ $c_{\mathrm{c}}, c_{\mathrm{k}}$ : location of neutral axis \\ CBX: closed box shear-head \\ CRH: cruciform shear-head made of I sections or back-to-back welded \\ channels \\ CTP: cruciform shear-head with two-way two pair of channels running at the \\ column \\ support $d$ : bending effective depth \\ $d_{0}$ : shear effective depth \\ $d_{\mathrm{g} 0}, d_{\mathrm{g}}$ : aggregate size \\ $d_{\mathrm{vfb}}$ : centroid of bottom flange \\ $E_{\mathrm{c}}$ : elastic concrete modulus \\ $E_{\mathrm{s}}, E_{\mathrm{v}}$ : steel elastic modulus \\ $f_{\mathrm{c}}$ : concrete strength \\ $f_{\mathrm{ct}}$ : tensile strength of concrete \\ $f_{\text {ys }}$ : reinforcement yield strength \\ $f_{\mathrm{yv}}$ : shear-head yield strength
}

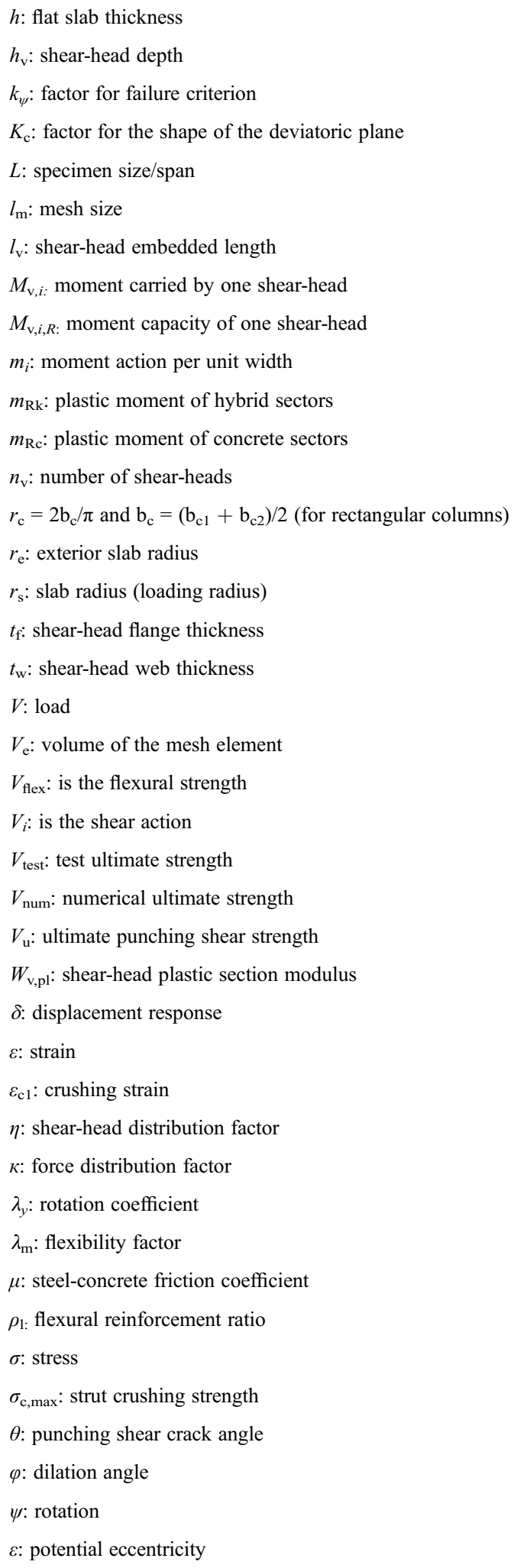

$V_{\mathrm{e}}$ : volume of the mesh element

$V_{\text {flex }}$ : is the flexural strength

$V_{i}$ : is the shear action

$V_{\text {test }}$ : test ultimate strength

$V_{\text {num }}$ : numerical ultimate strength

$V_{\mathrm{u}}$ : ultimate punching shear strength

$W_{\mathrm{v}, \mathrm{pl}}$ : shear-head plastic section modulus

$\delta$ : displacement response

$\varepsilon$ : strain

$\varepsilon_{\mathrm{c} 1}$ : crushing strain

$\eta$ : shear-head distribution factor

$\kappa$ : force distribution factor

$\lambda_{y}$ : rotation coefficient

$\lambda_{\mathrm{m}}$ : flexibility factor

$\mu$ : steel-concrete friction coefficient

$\rho_{1:}$ flexural reinforcement ratio

$\sigma$ : stress

$\sigma_{\mathrm{c}, \text { max }}:$ strut crushing strength

$\theta$ : punching shear crack angle

$\varphi$ : dilation angle

$\psi$ : rotation

$\varepsilon:$ potential eccentricity

\section{References}

1. Lips S, Fernández Ruiz M, Muttoni A. Experimental investigation on punching strength and deformation capacity of shear-reinforced slabs. ACI Structural Journal, 2012, 109: 889-900 
2. Park $\mathrm{H}$ G, Kim $Y$ N, Song J G, Kang S M. Lattice shear reinforcement for enhancement of slab-column connections. Journal of Structural Engineering, 2012, 138(3): 425-437

3. Gosav A V, Kiss Z I, Oneț T, Bompa D V. Failure assessment of flat slab-to-column members. Magazine of Concrete Research, 2016, 68(17): 887-901

4. Bryl S. Flat slabs with shear-heads. Schweizerische Bauzeitung, 1969, 87(10): 181-183 (in German)

5. Gomes R, Regan P. Punching strength of slabs reinforced for shear with offcuts of rolled steel I-section beams. Magazine of Concrete Research, 1999, 51(2): 121-129

6. Corley W G, Hawkins N M. Shear-head reinforcement for slabs. ACI Journal Proceedings, 1968, 65(10): 811-824

7. Hawkins N W, Corley W G. Moment transfer to columns in slabs with shear-head reinforcement. Special Publication, 1974, 42: 847880

8. Al-Hamd R K, Gillie M, Cunningham L S, Warren H, Albostami A S. Novel shear-head reinforcement for slab-column connections subject to eccentric load and fire. Archives of Civil and Mechanical Engineering, 2019, 19(2): 503-524

9. Ngekpe B, Abbey S, Olubanwo A. Structural performance of a modified shear-head assembly for edge steel column embedded in reinforced concrete slab. Engineering Solid Mechanics, 2019, 7(1): $59-70$

10. Gilbert S G, Glass C. Punching failure of reinforced concrete flat slabs at edge columns. Structural Engineer. Part B, 1987, 65: $16-28$

11. Kenel A, Keller T. External Steel Shear Heads for Retroactive Enhancement of Punching Shear Strength in Existing Flat Slabs. Technical Report. F. J. Aschwanden AG, CH-3250. 2013

12. Bompa D V, Elghazouli A Y. Structural performance of RC flat slabs connected to steel columns with shear-heads. Engineering Structures, 2016, 117: 161-183

13. Kahn J. US Patent, 926,497. 1909

14. Hardison R M. US Patent, 1,550,317. 1925

15. Wheeler $\mathrm{W} H$. Thin flat-slab floors prove rigid under test. Engineering News Record, 1936, 116(2): 49-50

16. Godycki T, Kozicki J. Eccentrically loaded interior slab-column connections with shear-head reinforcement. Materials and Structures, 1984, 17(2): 145-148

17. Majeed M M, Abbas A N. Punching shear strength characteristics of flat plate panels reinforced with shear-head collars: Experimental investigation. Civil Engineering Journal, 2019, 5(3): 528-539

18. Huber K M, Bryl S. Discussion of "Shear reinforcement for concrete slabs" by Walter H. Dilger and Amin Ghali (December, 1981). Journal of Structural Engineering, 1984, 110(1): 169-171

19. Frangi T, Tonis D, Muttoni A. Assessment of column supports made of steel. Schweizer Ingenieur und Architekt, 1997, 1997: 12-14 (in German)

20. Chana P S, Birjandi F K. Design Guidance on Structural Steel Shear-Heads in Concrete (Shear-Head Development Tests). Concrete Research and Innovation Centre, Imperial College, London. Report No. CRIC95/001/F. 1996

21. Piel W, Hanswille G. Composite shear-head systems for improved punching shear resistance of flat slabs. Construction in Steel and Concrete, 2006, V: 226-235
22. Elghazouli A Y, Izzuddin B A. Realistic modeling of composite and reinforced concrete floor slabs under extreme loading. II: Verification and application. Journal of Structural Engineering, 2004, 130(12): 1985-1996

23. Castro J M, Elghazouli A Y, Izzuddin B A. Modelling of the panel zone in steel and composite moment frames. Engineering Structures, 2005, 27(1): 129-144

24. Castro J M, Elghazouli A Y, Izzuddin B A. Assessment of effective slab widths in composite beams. Journal of Constructional Steel Research, 2007, 63(10): 1317-1327

25. Lemaitre J. Evaluation of dissipation and damage in metals submitted to dynamic loading. In: Proceedings of International Conference of Mechanical Behavior of Materials 1 (ICM 1). Kyoto: The Society of Material Science, 1971, 1-20

26. Bažant $\mathrm{Z} \mathrm{P}, \mathrm{Oh} \mathrm{B} \mathrm{H}$. Crack band theory for fracture of concrete. Matériaux et Constructions, 1983, 16(3): 155-177

27. Jirásek M, Zimmermann T. Rotating crack model with transition to scalar damage. Journal of Engineering Mechanics, 1998, 124(3): 277-284

28. Ozbolt J. Size effect and ductility of concrete and reinforced concrete structures. Dissertation for Habilitation. Stuttgart: Universität Stuttgart, 1995

29. Rabczuk T, Akkermann J, Eibl J. A numerical model for reinforced concrete structures. International Journal of Solids and Structures, 2005, 42(5-6): 1327-1354

30. Bittencourt T N, Wawrzynek P A, Ingraffea A R, Sousa J L. Quasiautomatic simulation of crack propagation for 2D LEFM problems. Engineering Fracture Mechanics, 1996, 55(2): 321-334

31. Loehnert S, Belytschko T. A multiscale projection method for macro/microcrack simulations. International Journal for Numerical Methods in Engineering, 2007, 71(12): 1466-1482

32. Oliyer J. Continuum modelling of strong discontinuities in solid mechanics using damage models. Computational Mechanics, 1995, 17(1-2): 49-61

33. Areias P, Rabczuk T. Finite strain fracture of plates and shells with configurational forces and edge rotations. International Journal for Numerical Methods in Engineering, 2013, 94(12): 1099-1122

34. Areias P, Rabczuk T, Camanho P P. Finite strain fracture of $2 \mathrm{D}$ problems with injected anisotropic softening elements. Theoretical and Applied Fracture Mechanics, 2014, 72: 50-63

35. Teng X, Wierzbicki T. Evaluation of six fracture models in high velocity perforation. Engineering Fracture Mechanics, 2006, 73(12): $1653-1678$

36. Oliver J. A consistent characteristic length for smeared cracking models. International Journal for Numerical Methods in Engineering, 1989, 28(2): 461-474

37. Fan R, Fish J. The RS-method for material failure simulations. International Journal for Numerical Methods in Engineering, 2008, 73(11): 1607-1623

38. Swenson D V, Ingraffea A R. Modeling mixed-mode dynamic crack propagation using finite elements: Theory and applications. Computational Mechanics, 1988, 3(6): 381-397

39. Camacho G T, Ortiz M. Computational modelling of impact damage in brittle materials. International Journal of Solids and Structures, 1996, 33(20-22): 2899-2938

40. Lilliu G, van Mier J G M. Simulation of 3D crack propagation with 
the lattice model. In: Proceedings of the International Congress on Advanced Materials, Processes and Applications (Materials Week). Frankfurt: Bauverlag BV GambH, 2000

41. Oliver J. On the discrete constitutive models induced by strong discontinuity kinematics and continuum constitutive equations. International Journal of Solids and Structures, 2000, 37(48-50): 7207-7229

42. Song J H, Areias P M A, Belytschko T. A method for dynamic crack and shear band propagation with phantom nodes. International Journal for Numerical Methods in Engineering, 2006, 67(6): 868893

43. Rabczuk T, Belytschko T. Cracking particles: A simplified meshfree method for arbitrary evolving cracks. International Journal for Numerical Methods in Engineering, 2004, 61(13): 2316-2343

44. Rabczuk T, Zi G. A meshfree method based on the local partition of unity for cohesive cracks. Computational Mechanics, 2007, 39(6): 743-760

45. Rabczuk T, Zi G, Bordas S, Nguyen-Xuan H. A geometrically nonlinear three-dimensional cohesive crack method for reinforced concrete structures. Engineering Fracture Mechanics, 2008, 75(16): $4740-4758$

46. Rabczuk T, Belytschko T. Application of particle methods to static fracture of reinforced concrete structures. International Journal of Fracture, 2006, 137(1-4): 19-49

47. Rabczuk T, Belytschko T. A three-dimensional large deformation meshfree method for arbitrary evolving cracks. Computer Methods in Applied Mechanics and Engineering, 2007, 196(29-30): 27772799

48. Rabczuk T, Zi G, Bordas S, Nguyen-Xuan H. A simple and robust three-dimensional cracking-particle method without enrichment. Computer Methods in Applied Mechanics and Engineering, 2010, 199(37-40): 2437-2455

49. Rabczuk T, Bordas S, Zi G. On three-dimensional modelling of crack growth using partition of unity methods. Computers and Structures, 2010, 88(23-24): 1391-1411

50. Areias P, Msekh M A, Rabczuk T. Damage and fracture algorithm using the screened Poisson equation and local remeshing. Engineering Fracture Mechanics, 2016, 158: 116-143

51. Areias P, Rabczuk T. Steiner-point free edge cutting of tetrahedral meshes with applications in fracture. Finite Elements in Analysis and Design, 2017, 132: 27-41

52. Areias P, Rabczuk T, Msekh M A. Phase-field analysis of finitestrain plates and shells including element subdivision. Computer Methods in Applied Mechanics and Engineering, 2016, 312: 322350

53. Areias P, Reinoso J, Camanho P P, César de Sá J, Rabczuk T. Effective $2 \mathrm{D}$ and $3 \mathrm{D}$ crack propagation with local mesh refinement and the screened Poisson equation. Engineering Fracture Mechanics, 2018, 189: 339-360

54. Kachanov L. Rupture time under creep conditions. Izvestiia Akademii Nauk SSSR. Seriia Khimicheskaia, 1958, 8: 26-31

55. Cicekli U, Voyiadjis G Z, Abu Al-Rub R K. A plasticity and anisotropic damage model for plain concrete. International Journal of Plasticity, 2007, 23(10-11): 1874-1900

56. Grassl P, Jirásek M. Damage-plastic model for concrete failure. International Journal of Solids and Structures, 2006, 43(22-23):
7166-7196

57. Lee J, Fenves G L. Plastic-damage model for cyclic loading of concrete structures. Journal of Engineering Mechanics, 1998, 124(8): 892-900

58. Xu B, Bompa D V, Elghazouli A Y, Ruiz-Teran A M, Stafford P J. Behaviour of rubberised concrete members in asymmetric shear tests. Construction \& Building Materials, 2018, 159: 361-375

59. Bompa D V, Elghazouli A Y. Monotonic and cyclic performance of threaded reinforcement splices. Structures, 2018, 16: 358-372

60. Gorga R V, Sanchez L F, Martín-Pérez B. FE approach to perform the condition assessment of a concrete overpass damaged by ASR after 50 years in service. Engineering Structures, 2018, 177: 133146

61. Belletti B, Muttoni A, Ravasini S, Vecchi F. Parametric analysis on punching shear resistance of reinforced concrete continuous slabs. Magazine of Concrete Research, 2018, 12: 1-32

62. Marí A, Cladera A, Oller E, Bairán J M. A punching shear mechanical model for reinforced concrete flat slabs with and without shear reinforcement. Engineering Structures, 2018, 166: 413-426

63. Wosatko A, Pamin J, Polak M A. Application of damage-plasticity models in finite element analysis of punching shear. Computers \& Structures, 2015, 151: 73-85

64. Moharram M I, Bompa D V, Elghazouli A Y. Performance and design of shear-keys in hybid RC beam and steel column systems. Ce/Papers, 2017, 1(2-3): 2031-2040

65. Bompa D V, Elghazouli A Y. Force transfer mechanisms between steel columns and reinforced concrete beams by means of shear keys. In: Proceedings of EUROSTEEL 2014: The 7th European Conference on Steel and Composite Structures. Napoli: ECCS, 2014, 10-12

66. Behnam H, Kuang J S, Samali B. Parametric finite element analysis of RC wide beam-column connections. Computers \& Structures, 2018, 205: 28-44

67. Nzabonimpa J D, Hong W K, Kim J. Nonlinear finite element model for the novel mechanical beam-column joints of precast concretebased frames. Computers \& Structures, 2017, 189: 31-48

68. Eder M A, Vollum R L, Elghazouli A Y, Abdel-Fattah T. Modelling and experimental assessment of punching shear in flat slabs with shear-heads. Engineering Structures, 2010, 32(12): 3911-3924

69. Bompa D V, Elghazouli A Y. Numerical modelling and parametric assessment of hybrid flat slabs with steel shear heads. Engineering Structures, 2017, 142: 67-83

70. Bompa D V, Elghazouli A Y. Ultimate behaviour and design of hybrid flat slabs with steel shear heads. Ce/Papers, 2017, 1(2-3): 2310-2319

71. Burley B, Boothby T. Medical Office Building Malvern, PA. Final Report. Penn State University, Technical Report. 2005

72. Gnädinger M N. Punching shear strength of flat slabs with shearheads. Thesis for the Master's Degree. Lucerne: Hochschule Luzern, 2011

73. De Sutter K. Numerical investigation of the punching shear behaviour of flat plates with column head strengthening. Thesis for the Master's Degree. Munchen: Technische Universitat Munchen, 2015

74. Hugenschmidt J, Fischer A, Schiavi L. Investigation of punching reinforcement in flat slabs. Beton- und Stahlbetonbau, 2014, 109(4): 
257-264 (In German)

75. Zhang A, Ma X, Fang H, Mu J, Liu T. Seismic behaviour of connections between prefabricated RC flat slabs and square steel tube columns. Engineering Structures, 2018, 173: 800-812

76. Kim J W, Lee C H, Kang T H K. Shear-head reinforcement for concrete slab to concrete-filled tube column connections. ACI Structural Journal, 2014, 111(3): 629-638

77. BCA (British Cement Association). Prefabricated Punching Shear Reinforcement for Reinforced Concrete Flat Slabs. Technical Report. 2001

78. CEN (European Committee for Standardization). EN 1992-1-1. Eurocode 2: Design of Concrete Structures-Part 1-1: General Rules and Rules for Buildings. Brussels: CEN, 2004

79. The International Federation for Structural Concrete: FIB. FIB Bulletin No. 66-Model Code 2010-Final draft, Vol 2. Lausanne: The International Federation for Structural Concrete: FIB, 2012

80. ACI (American Concrete Institute). ACI 318M-14 Building Code Requirements for Structural Concrete and Commentary. Farmington Hills, MI: ACI, 2014

81. Guandalini S, Burdet O L, Muttoni A. Punching tests of slabs with low reinforcement ratios. ACI Structural Journal, 2009, 106: 87-95

82. DSS (Dassault Systèmes Simulia Corp). ABAQUS Analysis User's Manual 6.14-2. Providence, RI: DSS, 2014
83. Moharram M I, Bompa D V, Elghazouli A Y. Experimental and numerical assessment of mixed RC beam and steel column systems. Journal of Constructional Steel Research, 2017, 131: 51-67

84. Hordijk D A. Local approach to fatigue of concrete. Dissertation for the Doctoral Degree. Delft: Delft University of Technology, 1991

85. Bompa D V, Onet T. Punching shear strength of RC flat slabs at interior connections to columns. Magazine of Concrete Research, 2016, 68(1): 24-42

86. Genikomsou A S, Polak M A. Finite element analysis of punching shear of concrete slabs using damaged plasticity model in ABAQUS. Engineering Structures, 2015, 98: 38-48

87. Bompa D V, Onet T. Identification of concrete damaged plasticity constitutive parameters. In: The National Technical Scientific Conference - Modern Technologies for the 3rd Millenium. Oradea: University of Oradea, 2010

88. Baltay P, Gjelsvik A. Coefficient of friction for steel on concrete at high normal stress. Journal of Materials in Civil Engineering, 1990, 2(1): 46-49

89. Rabbat B G, Russell H G. Friction coefficient of steel on concrete or grout. Journal of Structural Engineering, 1985, 111(3): 505-515

90. Muttoni A. Punching shear strength of reinforced concrete slabs without transverse reinforcement. ACI Structural Journal, 2008, 105(4): 440-450 